\title{
LA VOZ FEMENINA EN ALBACETE. SOPRANOS DESTACADAS EN LA SEGUNDA MITAD DEL SIGLO XX
}

\author{
THE FEMALE VOICE IN ALBACETE. PROMINENT SOPRANO \\ SINGERS IN THE SECOND HALF OR THE TWENTIETH CENTURY
}

\author{
María del Valle De Moya Martínez \\ Universidad de Castilla-La Mancha \\ Albacete, España \\ mariavallede.moya@uclm.es
}

Maria del Valle Robles De Moya

Investigadora independiente

Albacete, España

mariadelvalle21@gmail.com

Cómo citar este artículo: Moya Martínez de, Mํㅡㄹ del; Robles de Moya, Mํㅡㄹ del. (2021). La voz femenina en Albacete. Sopranos destacadas en la segunda mitad del siglo XX. Al-Basit (66), 333-398. http://doi.org/10.37927/al-basit.66_9

Recibido/Received: 17-06-2021

Aceptado/Accepted: 29-07-2021

\section{RESUMEN}

El presente trabajo desarrolla una investigación dedicada a la recuperación del patrimonio artístico musical en la historia reciente de la ciudad de Albacete. Así, se ha buscado conocer cuáles fueron las figuras femeninas más destacadas en la ciudad durante la segunda mitad del siglo XX; en concreto, las voces pertenecientes a la cuerda de soprano. Para ello, se ha seleccionado una serie de cantantes formadas en el Conservatorio de Albacete en la segunda mitad del siglo XX, originarias de Albacete o que se han desarrollado profesionalmente en esta ciudad, y que han contribuido, con sus trayectorias en diferentes ámbitos profe-

\section{ABSTRACT}

This research is devoted to the recovery of the musical artistic heritage in the recent history of the city of Albacete. Thus, this paper sought to find out which were the most outstanding female figures in the city during the second half of the 20th century; specifically, the soprano singers. To this end, a series of relevant female singers has been selected. These singers were born in Albacete or have developed their professional career in this city, contributing with their careers in different professional fields to maintain and increase the musical legacy of Albacete. To contextualize the aforementioned research, information has been gathered on 
sionales, a mantener e incrementar el legado musical albaceteño. Para contextualizar la citada investigación, se han revisado los planes de estudio reglados de la especialidad de Canto en la España del siglo $\mathrm{XX}$, en el ámbito educativo específico del Conservatorio. En concreto, el foco del desarrollo lírico albaceteño localizado en el primer centro educativo oficial de la provincia: el Real Conservatorio de Música de la Excma. Diputación Provincial. Por salirse de los límites cronológicos y temáticos establecidos, sólo se ha mencionado al Conservatorio de Música Profesional «Tomás de Torrejón y Velasco» y al Conservatorio Superior de Música de Castilla-La Mancha, ambos dependientes de la Consejería de Educación de la Junta de Comunidades de CastillaLa Mancha. Con la intención de aportar al estudio una visión personal, humana y veraz, siguiendo el modelo de historias de vida o microhistorias, y aplicando un enfoque cualitativo, se entrevistaron a las sopranos seleccionadas para valorar sus aportaciones a la vida musical de la ciudad. Se diseñaron entrevistas con veinte preguntas para recabar datos, ya fuera de forma presencial o virtual, sobre su formación y desarrollo profesional, dentro y fuera de Albacete. Así se ha conseguido recuperar sus recuerdos y calibrar sus diversas influencias en el desarrollo cultural y musical de la ciudad.

PALABRAS CLAVE: historia de la vida musical de Albacete, recuperación del patrimonio musical albacetense, Conservatorio Profesional de la Excma. Diputación Provincial de Albacete, sopranos albaceteñas, siglo XX. the study plans of Spanish Conservatories of Music for the specialty of singing in 20th Century. A specific focus of the lyrical development in Albacete was located in the first official educational center in the province: the Royal Conservatoire of Music of the Provincial Council of Albacete. In order to go beyond the established chronological and thematic limits, only the Professional Conservatory of Music «Tomás de Torrejón y Velasco» and the «Conservatorio Superior de Música de Castilla-La Mancha», both dependent on the "Consejería de Educación de la Junta de Comunidades de Castilla-La Mancha», have been mentioned. In an attempt to provide the study with a personal, human, and truthful vision, following the model of life stories or microstories, the selected sopranos were interviewed to assess their contributions to the musical life of the city. Online questionnaires and personal interviews were designed with twenty questions and a qualitative approach, collecting data on their training and professional development, inside and outside of Albacete. Therefore, the memories and influences on the cultural and musical development of the city were retrieved.

KEYWORDS: history of the musical live of Albacete, recovery of the musical heritage of Albacete, Professional Conservatory of the Excellent Provincial Deputy of Albacete, soprano singers of Albacete, $20^{\text {th }}$ Century. 


\section{JUSTIFICACIÓN}

En la elaboración de la presente investigación se ha tenido presente una concepción de la voz como instrumento comunicativo, musical, artístico y sentimental. Antes que ofrecer una mera descripción de sucesos y situaciones se ha buscado abordar un conjunto de hechos históricos y las vivencias personales de los mismos, las de las protagonistas de la historia recreada, con la intención de contextualizar correctamente los estudios y actividades de Canto y de las cantantes en la historia reciente de Albacete. Para establecer una correcta relación entre descripción, teoría y realidad se ha recurrido a la investigación de corte cualitativo, basada en cuestionarios y entrevistas personales, posibilitando la creación de historias de vida, una de las técnicas usadas en los métodos de la reconstrucción histórica (Arias, 2014; Ronen, 2013).Por tanto, el principal objetivo de este estudio ha sido el de conocer, preservar y divulgar el papel artístico musical, cultural, académico y social que tuvieron diferentes y reconocidas sopranos durante el devenir de la ciudad durante la segunda mitad del siglo XX. Es decir, investigar la historia personal de aquellas sopranos de Albacete que se formaron en el Conservatorio de Música de la Excma. Diputación Provincial en la segunda mitad del siglo XX, teniendo como fuente principal sus testimonios y recuerdos en primera persona. En consecuencia, se derivan otros objetivos secundarios como son: recorrer el panorama legislativo de los planes de estudio de la especialidad de Canto que estuvieron vigentes en España durante el siglo XX. Y recuperar parte del patrimonio musical de la ciudad de Albacete a través del desarrollo del canto lírico irradiado desde el Conservatorio.

\section{INTRODUCCIÓN}

En referencia a la centuria romántica, recordar que:

Este fue el contexto tanto social como estético en el que la voz de soprano estableció su reinado definitivo, puesto que sus caracter- 
ísticas eran las que mejor cubrían las nuevas necesidades expresivas y las que mejor se adaptaban a las nuevas condiciones materiales (Peralta, 2018, p. 25).

\subsection{Antecedentes: el arte lírico español a finales del siglo XIX}

En España, el año 1868 fue decisivo en lo político, económico, social y cultural, por iniciarse el Sexenio Revolucionario, al que seguiría la I República, la Restauración Borbónica de Alfonso XII, la Regencia de María Cristina y el Desastre del 98 con el que se terminaba un siglo y una era para la Nación Española (Juliá, Ringrose y Segura 1995). Los años 70 del siglo XIX fue una época muy característica y fructífera en todo el panorama artístico español; en concreto, el musical, ya que la música plasmaba todo aquello que sucedía a su alrededor (Borrell, 1912).Así, se consolidan las revistas especializadas musicales y se genera la crítica musical en la prensa periódica, consecuencia de la influencia social de la expansión de la música, en concreto, de los géneros líricos de Ópera y Zarzuela y de los intentos de compositores e intelectuales por crear la Ópera Nacional Española (Casares, 1995).

Musicalmente, el siglo XIX español vivió tres grandes hitos localizados en Madrid, capital del reino: la creación del Real Conservatorio de Música y Declamación de María Cristina, gracias a la Reina, el 15 de julio de 1830, el primer germen de cultura musical que buscó irradiarse a nivel nacional por ser el primer centro musical y el modelo a seguir en el resto de las ciudades españolas. La construcción del Teatro Real como sede del arte lírico por orden de Isabel II en 1850. El nacimiento de la Sección de Música de la Real Academia de Artes de San Fernando creada el 12 de julio de 1752 por el Rey Felipe V, la cual se mantendría y prosperaría gracias a los diferentes artistas y monarcas de la Historia de España hasta nuestros días. Hubo que esperar más de un siglo y la llegada de la Primera República para que Emilio Castelar incluyese en 1873 un cuarto arte: la música, a pesar de la oposición de muchos académicos (De Moya, 2013). 
Durante el Sexenio Revolucionario (1868-1874), el Teatro Real de Madrid pasó a llamarse Teatro Nacional de la Ópera o Teatro Nacional de la Ópera Italiana, del mismo modo que el Real Conservatorio de María Cristina cambió su denominación a la de Escuela Nacional de Música y Declamación (Gómez de la Serna, 1976). El Real Conservatorio, o Escuela Nacional, satisfizo las demandas de la burguesía, que había puesto de moda el estudio y la interpretación musical en diferentes campos. Sin embargo, no fueron buenos años para el Conservatorio, que sufrió recortes económicos: falta de profesorado, salarios bajos, poca dotación económica, entre otros. Lo único que supuso una mejora en esta época fue el nombramiento de Arrieta como Director del centro (Sopeña, 1967). Con la Restauración (1875-1885), tanto el alumnado del Real Conservatorio de Madrid como el público del Real, se fueron cansando del exceso de extranjerismo musical, de óperas italianas, alemanas y francesas, surgiendo un sentimiento de españolismo cultural. Gracias a Arrieta, director del Real Conservatorio, en las clases de canto se aumentó la dedicación a la canción española y Zarzuela. La matrícula femenina era muy superior a la masculina ya que se entendía que la docencia musical era un camino decoroso para una mujer. Además, el Conservatorio inauguró la matrícula libre, lo que facilitó el aumento de alumnas que veían en la música una próspera salida profesional como profesoras de piano o cantantes. A la vez, la educación coral experimentó un auge y un reconocimiento de su importancia en la composición de óperas y zarzuelas (Peña y Goñi, 1881).

El Real Conservatorio de Madrid se caracterizó por el apoyo al establecimiento de la Ópera Nacional, de las que fueron sus grandes impulsores Bretón y Chapí, y con el apoyo de la escuela nacionalista alentada por Felipe Pedrell. Pero la negatividad moral y social imperante en los últimos años del siglo XIX, no favoreció al Conservatorio que también se vio afectado por la crisis del Desastre del 98 (Sopeña, 1967). Esta época asistió al esplendor de la Zarzuela, la Ópera Española, el Género Chico y el Sainete Lírico, gracias a las composiciones de Arrieta, Serrano, Chapí, Bretón, Caballero, Chueca 
y Valverde. La nueva generación de músicos españoles quiso hacer realidad el sueño de la Ópera Española, pero el género no llego a triunfar a diferencia del Género Chico (Muñoz, 1965).

Por su parte, el Real Conservatorio se caracterizó por el establecimiento de la Ópera Nacional, siendo los mayores precursores Bretón y Chapí, y con el apoyo de la escuela nacionalista de Pedrell. Se sucedieron los cambios en la dirección de Jesús de Monasterio y de Ildefonso Jimeno, directores del conservatorio. Pero la negatividad imperante tanto moral como social en los últimos años de siglo no favorecieron al Conservatorio, al que llevó también el declive propiciado por el Desastre de 1898 (Sopeña, 1967).

\subsection{Los Conservatorios en España}

El término conservatorio deriva del italiano siendo sinónimo de asilo, hospicio o centro benéfico donde se acoge a huérfanos y se les ofrece una enseñanza musical para que participen en actos litúrgicos al tiempo que se les brinda un mínimo de protección. Hoy día, con este término se hace referencia a centros educativos públicos donde se oferta una enseñanza oficial de la música, el canto y la danza (https://dle.rae.es/conservatorio).

Los primeros conservatorios surgieron en Italia durante el Renacimiento dedicados en un primer momento a formar a jóvenes en riesgo de exclusión social en el canto, aunque posteriormente, se fueron incorporando aprendizajes de instrumentos. En el siglo XVIII aparece la primera Escuela Real de Canto y Declamación en Francia (1783) que tras la Revolución pasó a llamarse Institut National de Musique y dos años después se convirtió en el primer Conservatorio Nacional de Música de toda Europa. En esta línea aparecieron también por todas las capitales europeas diferentes conservatorios de música mostrando cómo se organizaba la enseñanza musical desligada ya de las capillas musicales eclesiásticas y de los patrocinadores y mecenas aristocráticos para estar más al servicio de la pujante clase burguesa (Sarget, 2000). En España, el primer conser- 
vatorio se funda en Madrid en 1830 bajo la protección de la Reina María Cristina, la madre de Isabel II. Poco a poco, estos centros educativos se irían expandiendo por el territorio nacional aunque sin reconocimiento oficial. Así, el de Barcelona (1838); el de las Islas Baleares (1881); el del Liceo (1847); el de Málaga (1880); el de Valencia (1879); el de Bilbao (1878); el de Oviedo (1887);el de Sevilla (1889) (Haro-Almansa, van Zummeren-Moreno, 2017).

Las directrices musicales impuestas por la nueva clase social dominante, la burguesía, contribuyeron a la creación de espacios y salas cada vez mayores que requerían voces capaces de llenarlas, financiando a orquestas y a compositores para la creación e interpretación de más obras. Se cree que este momento fue el decisivo para la vida y la fama de la cuerda soprano:

Este fue el contexto tanto social como estético en el que la voz de soprano estableció su reinado definitivo, puesto que sus características eran las que mejor cubrían las nuevas necesidades expresivas y las que mejor se adaptaban a las nuevas condiciones materiales (Peralta, 2018, p. 25).

Ya en el siglo XX, y gracias a la Ley de Educación Nacional de 1942, se establecieron en España los siguientes Conservatorios Profesionales: Conservatorios de Córdoba, Málaga, Murcia, Sevilla, Valencia, Bilbao, Zaragoza, Tenerife y Coruña. También aquellos subvencionados o con validez académica de Cádiz, Salamanca, Oviedo, Baleares, Cartagena, Ceuta, San Sebastián, Santander, Vitoria, Valladolid, y la Escuela Municipal de Música de Barcelona.

\subsection{El Real Conservatorio de Música y Danza de la Excelentísi- ma Diputación de Albacete}

Ya se ha mencionado que el primer conservatorio que hubo en España fue el Real Conservatorio de Música y Declamación de Madrid, en 1830. Los dos tercios de siglo que restaban vieron cómo 
surgían diferentes conservatorios por toda la geografía nacional. Esta red educativa musical se amplió y consolidó durante el siglo $\mathrm{XX}$, sobre todo en la segunda mitad, aunque muchos de los conservatorios tenían titularidad municipal, provincial (por depender directamente de las Diputaciones) y pocos eran los que dependían del Ministerio, grupo en el que se incluían todos los Superiores.

A mediados de la pesada centuria, con los necesarios reajustes que trajo consigo el fin de la contienda civil (1936-1939), se promulga el Plan de Estudios musicales de 1942, por el que se elevan a rango de Conservatorio Profesional muchas escuelas de música existentes de titularidad local o provincial. Este hecho favoreció tremendamente la difusión cultural y el acceso a estudios musicales reglados entre la población de provincias (Ley de Educación Nacional de 1942) (Decreto de 26 de enero de 1944).

En este contexto es donde tenemos que insertar el primer conservatorio que hubo en Albacete, el Real Conservatorio Profesional de Música y Escuela de Danza, fundado en 1951, de grado elemental, bajo la titularidad de la Excma. Diputación Provincial de Albacete y sigue funcionando en nuestros días, tras adquirir la categoría de centro profesional. Actualmente, es un centro oficial, público, dependiente de la Diputación Provincial de Albacete que imparte enseñanzas de Música, Canto y Danza. Se encuentra acogido en un edificio catalogado como monumento artístico, el antiguo Monasterio de la Encarnación, más tarde Casa de la Maternidad, institución benéfica que también dependía de la Diputación Provincial. Está ubicado entre las calles Padre Romano y Las Monjas (Apuntes Musicales, 2011).

En 1949, la Sección de Gobierno de la Diputación Provincial de Albacete refleja la posibilidad de crear en la ciudad un centro que atienda a las demandas educativas artísticas referentes a la Música y la Danza. A partir de abril de ese mismo año, se designó como Presidente de la Corporación a Herminio Picazo Bermejo, que gestionó la creación del Conservatorio junto con los vocales Pedro Madrona Navarro y José Aguilar Espinosa. También contribuyeron 
en este proyecto el Presidente de la Sección de Educación, Deportes y Turismo, Andrés Masiá Martí, el director de la Banda Municipal de Albacete, Daniel Martín Rodríguez y las señoras Carmen Ibáñez Ibáñez, profesora de Música de la Escuela Normal de Magisterio, e Isabel Fresno, Delegada Provincial de la Sección Femenina (Ballesteros, 1992).

Lógicamente, la prensa local se hizo eco de todas las noticias y novedades que estuvieran relacionadas con el Centro. Así, el miércoles 1 de noviembre de 1950, el periódico Albacete, en la sección fija titulada Vida Local, publicaba la siguiente noticia bajo el título La Diputación y el Conservatorio de Música (p. 2).

El Presidente y los Diputadores señores Aguilar y Masía, visitan el local donde será instalado (AHP, Carpeta 131): ... El Conservatorio de Música y Declamación, ocupará una de las naves laterales del edificio de la Casa de Maternidad, quedando así completamente independiente de lo que hoy es residencia de niños acogidos por la Beneficencia...

La semana siguiente, el 7 de noviembre de 1950, la misma fuente, periódico Albacete, seguía informando a la ciudadanía sobre asuntos relacionados con el Conservatorio, en la sección denominada Vida local. Un Conservatorio de Música y Declamación; esta vez, para referirse al plan de estudios (AHP, Carpeta 131): ...En él cursarán las asignaturas de Armonía, Piano, Violín, Canto y Solfeo, así como las de las distintas disciplinas llamadas especiales: instrumentos de pulso y declamación y teatro...

El 29 de noviembre de 1950 se fundó el Conservatorio. Y se encargó a la Sección de Educación la elaboración de un proyecto de reglamento y plantilla, que tendría que aprobarse por la Corporación Provincial. Finalmente, el acta del 29 de diciembre de 1950 dictamina que la Dirección General de Trabajo ha aprobado dicho proyecto, restando dar una ubicación al centro. El documento que se presentó al pleno constaba de quince epígrafes (Ballesteros, 1992, p. 12): 
Del objetivo del Conservatorio, de la enseñanza de las clases; del gobierno y dirección del conservatorio; del personal; del director del conservatorio; del secretario; de los profesores; de los auxiliares; sueldos y gratificaciones; del ingreso en el Conservatorio; de las obligaciones de los alumnos; de los exámenes; de los alumnos libres; de los empleados subalternos; y disposiciones finales.

Seguimos encontrado referencias en la prensa diaria local para destacar un hecho tan relevante como supuso la creación de un Conservatorio de Música en la ciudad, todo un acontecimiento cultural de primer orden. Así, el periódico Albacete. Diario de la tarde (Archivo Histórico Provincial, Carpeta 131), con fecha de 15 de diciembre de 1950, recogía bajo el epígrafe titulado De Música. Conservatorio de Música y Declamación:

El próximo día 29 en la sesión plenaria que celebrará la Corporación Provincial se expondrá para su aprobación, el reglamento por el que se ha de regir el nuevo conservatorio de música y declamación de Albacete creado por la Diputación Provincial. El día primero de Enero del próximo año, se abrirá la matrícula para que puedan solicitarla los alumnos que deseen cursar sus estudios en este centro docente. Al mismo tiempo podrán solicitar matrícula gratuita todas aquellas personas que acrediten la imposibilidad de sufragar los gastos de estudios, previo informe del director del centro elevado al Ilustrísimo señor presidente de la Diputación Provincial.

Pocos días después, el 30 de diciembre de 1950, el mismo periódico, Albacete, titulaba otra noticia en su última página: Don Daniel Martín y don José Espinosa, han sido nombrados director y secretario del Conservatorio de Música y Declamación (AHP, Carpeta 131):

A propuesta de la sección de educación de la Corporación provincial, han sido designados para el desempeño de los cargos de director y secretario del conservatorio de Música y Declamación don Daniel Martín Rodríguez, director de la Banda Municipal de Música y don José Espinosa Gascó, maestro de capilla y organista. 
El proyecto fue aprobado por unanimidad y se fijó la fecha de 1 de enero de 1951 para que empezase a funcionar aunque las clases comenzaron en febrero del mismo año, en un edificio de la Diputación, antiguo monasterio. El profesorado, al igual que los recursos, era escaso. La plantilla constaba de trece profesores y se eligió como director a Daniel Martín Rodríguez (Ballesteros, 1992). Nuevamente la prensa difundía la apertura oficial del Centro y las condiciones de matriculación de alumnos, insertando notas oficiales mandadas a la redacción por el Secretario académico, José Espinosa. Y lo publicaba en la sección fija denominada Vida local. Conservatorio Provincial de Música y Declamación. Convocatoria de matrícula para alumnos oficiales, el día 10 de enero de 1951 (AHP, Carpeta 132):

A partir del próximo 10 del corriente, queda abierto el plazo de matrícula para alumnos oficiales que desean cursar sus estudios en este Conservatorio Provincial de Música y Declamación. Los interesados que quieran solicitar petición de matrícula gratuita, pueden hacerlo en las oficinas de secretaría de este conservatorio (Padre Romano no 7, antiguo edificio de Maternidad), todos los días laborales de 7 a 8 de la tarde. El secretario JOSÉ ESPINOSA.

Dos días, después, el 12 de enero de 1951, se insistía y se recordaba al público el plazo de matriculación estipulado, en el mismo periódico, Albacete, y en la misma sección, Vida local. Conservatorio de Música y Declamación (AHP, Carpeta 132):

Se pone en conocimiento del público que el próximo día 20 del corriente, quedará cerrado el plazo de inscripción de matrícula de este conservatorio. Hasta dicha fecha, los interesados pueden matricularse de las asignaturas de solfeo, piano, violín, armonía, canto e instrumentos de pulso y púa (mandolina española, bandurria, laúd y guitarra) todos los días laborales de 7 a 8 de la tarde, en las oficinas provisionales de secretaría de este centro (Padre Romano no 7 antiguo edificio de maternidad). El secretario.

Desde sus inicios, el Conservatorio tenía la intención de participar en la vida pública de la ciudad y darse a conocer para mejo- 
rar la vida cultural de la ciudad y sus alrededores provinciales y lo demostró con la primera velada musical de Santa Cecilia, el 22 de noviembre de 1952. El éxito motivó que se repitiesen otras actuaciones memorables como la de 1956, con las actuaciones del Cuarteto de Cuerda de Madrid, Agrupación Nacional de Música de Cámara (Ballesteros, 1992). A partir de este momento, se fueron haciendo cada vez más actuaciones públicas con programas donde figuraban obras de Albéniz, Turina, Falla, Granados, Mompou, Gombau, entre otros, en un intento por dar a conocer y divulgar la música española más reciente.

Entre los años 1952-1955, las únicas asignaturas impartidas fueron Solfeo, Piano, Violín, Canto y Armonía. La profesora de Canto fue Concepción Fernández Cordero, quien también impartía solfeo. En febrero de 1954, por medio de un Decreto del Ministerio de Educación Nacional, se reconocen oficialmente las enseñanzas. El centro cambió su denominación a Real Conservatorio Elemental de Música, en sustitución del primitivo nombre de Conservatorio de Música y Declamación (Apuntes Musicales, 2011).

Desde 1956, se reconocían oficialmente los estudios de Canto desde primer curso; las clases de impartían en días alternos junto con la asignatura de Armonía mientras que Solfeo e Instrumentos tenían clases a diario (Ballesteros, 1992). Vemos que el Canto tenía poca presencia en esta época. Gracias a los esfuerzos de la profesora Conchita Fernández Cordero, y de la becaria Ma de los Llanos Pérez Raya, miembro del Orfeón San Pio X, se consiguieron mejorar la calidad de la música vocal coral del centro al incluir la participación del Orfeón en el Conservatorio.

A partir de 1974 se inicia una etapa de ampliación, incorporando al Conservatorio más recursos, materiales y humanos, aumentando las especialidades instrumentales y consolidando los estudios de Danza. Esta etapa puente finaliza en 1981, cuando el Centro se amplía y recibe el Grado Profesional (Apuntes Musicales, 2011). 
En 1979 el conservatorio tenía una gran cantidad de alumnos matriculados en todas las especialidades ofertadas. En la siguiente década, la fama del centro y su repercusión cultural aumentó, como lo prueba el homenaje ofrecido al que fuera primer Director del centro, Daniel Martín, con motivo de su jubilación, el 24 de marzo de 1979, en la Casa de la Cultura. Entre otras actuaciones, participaron las sopranos Ma de los Llanos Pérez Raya y María Isabel Martínez Martínez (Ballesteros, 1992).

En 1981 el Ministerio de Educación y Ciencia amplía las enseñanzas elementales a las de grado Profesional en todas las especialidades. Gracias a ello, la especialidad de Canto constará de seis cursos. En este mismo curso escolar de 1981-1982, Concepción Fernández Cordero se jubiló, Ma Llanos Pérez Raya dejó la Jefatura de Estudios y pasó a ser profesora de Canto del centro en 1983 hasta el año 2013, que cesa por motivo de su jubilación. Ocuparía la plaza de Canto su antigua alumna, la profesora Fuensanta Morcillo.

A mediados del pasado siglo, la Corporación Provincial de Albacete, se esforzó por dar ofrecer a la población una vía oficial de formación artístico musical, sobre todo, pensando en dar respuesta a las inquietudes musicales de los más jóvenes, ya que la finalidad de establecer un Conservatorio en la ciudad era la de educar y ampliar la cultura musical albaceteña. Buena prueba de su inquietud formativa fue la velada ofrecida el 22 de noviembre de 1952, con la actuación de uno de los grandes intérpretes del panorama nacional del momento, el pianista Leopoldo Querol, queriendo que la primera celebración de la festividad de Santa Cecilia fuese el inicio de una serie de conciertos y actividades artístico culturales organizadas desde el Conservatorio y ofertadas a toda la población (Apuntes Musicales, 2011).

La década de los noventa vive grandes cambios: en la estructura interna, el aumento de matrícula y la implantación de nuevas especialidades enfocadas al establecimiento de una orquesta. Igualmente, se impulsan las agrupaciones Instrumentales y Corales para potenciar las actividades complementarias que permitan hacer música grupal (Apuntes Musicales, 2011). 
En el curso 1991-1992, la Asociación de Padres de Alumnos crea una comisión preocupados por el futuro y las reformas educativas de la ley LOGSE del conservatorio. El conservatorio se había quedado pequeño y se esparcían los rumores acerca del cierre o traspaso del centro. Debido a la discusión este tema, existían relaciones entre la Diputación Provincial, la Delegación Provincial del Ministerio de Educación y Ciencia, Política Territorial de la Junta de Comunidades de Castilla-La Mancha y el Ayuntamiento de Albacete. Finalmente, el edificio de Bachillerato que se ubicaba en la calle Zapateros no 25 y que había servido de local de apoyo del Real Conservatorio, pasó a ser un conservatorio independiente (Ballesteros, 1992).

El nuevo Conservatorio, creado el 23 de octubre por Decreto Real del Ministerio de Educación, dependía del Ministerio, coexistiendo los dos centros educativos en la ciudad. En el año 2000, se traspasa su competencia a la Junta de Comunidades de Castilla-La Mancha y se le nombra como Tomás de Torrejón y Velasco en honor al músico albaceteño barroco. Tres años más tarde, en el 2003 se graduó la primera promoción de alumnos de Grado Medio dentro del plan de estudios LOGSE. Los profesores de Canto que ha tenido este otro Conservatorio albaceteño han sido José Ferrero, Fuensanta Morcillo y David Mancebón.

Diez años más tarde, el 4 de julio de 2013, se fundó en Albacete el primer Conservatorio Superior de Música; y en 2017, se graduó la primera promoción de alumnos del único Conservatorio Superior de toda la región de Castilla-La Mancha.

\subsection{Los planes de estudio de Canto del siglo XX}

Durante la segunda mitad de siglo, la enseñanza musical fue ganando en calidad gracias a la labor realizada en los conservatorios (Calderón, 2017).

El 15 de junio de 1942, el Ministerio de Educación Nacional, dirigido por el ministro José Ibáñez Martín, publicó el Decreto titu- 
lado Organización de los Conservatorios de Música y Declamación, derogando el Decreto de 1905 en el que, básicamente, se pedía que se reconociese por el Ministerio de Instrucción Pública y Bellas Artes la validez académica de los estudios elementales cursados en otros centros que estaban «asociados» al Conservatorio de Madrid. Se abre el documento jurídico afirmando que es preocupación primordial del Gobierno el resurgimiento de la cultura y del arte patrios y la educación de la sensibilidad pública con una sólida formación espiritual y artística, mediante una enseñanza bien organizada (DL BOE-A-1942-6043, de 15 de junio) queriendo abordar el problema de la educación musical, el arte dramático y la danza, artística y folklórica, considerando que no habían sido tratadas con el reconocimiento y respeto merecidos. Así, el objetivo principal del ministro era el de crear un "plan orgánico, eficaz y bien determinado» que reconociese las enseñanzas artísticas y tuviera profesionalidad en su impartición.

El único centro de docencia musical dependiente del Estado era el Real Conservatorio de Madrid (fundado en 1868 por la Reina María Cristina). Existían otros conservatorios (Real Decreto, 16 junio 1905) sin unificación a nivel nacional, siendo diferentes escuelas con distintas organizaciones, por lo que el Ministerio de Educación Nacional reorganizó los conservatorios españoles dividiendo las enseñanzas artísticas en tres niveles: elemental, profesional y superior (art. 1 LOCMD, de 15 de junio). Los Conservatorios Profesionales podían otorgar Títulos de Cantante, Enseñanzas de Declamación y Actor teatral (art. 2 LOCMD). En el Real Conservatorio de Música y Declamación de Madrid se cursaría Canto (escuela general); Canto lírico y dramático (Teatro); Canto de salón; Cursos superiores de último grado; Canto gregoriano; Rítmica y Paleografía; Dirección, realización y presentación teatral. Y contaría con clases «especiales» de Higiene práctica y Fisiología de la voz. Los Conservatorios Profesionales tendrían la especialidad de Canto y sus diversas especializaciones, uniendo Folklore y Canto Gregoriano con Rítmica y Paleografía constituyendo una única asignatura (art. 4 LOCMD). 
Los Conservatorios Elementales no tendrían enseñanzas de Solfeo y Nociones de Canto (art. 5 LOCMD). En este momento, el Real Conservatorio de Madrid pasa a tener carácter de Escuela Superior, ampliando, modificando o suprimiendo algunas enseñanzas, sin perjudicar al personal docente. Así se crean, de forma permanente, un grupo de enseñanzas superiores con carácter de virtuosismo en las especialidades de Piano, Violín, Dirección de orquesta, Musicología, Canto Gregoriano y Rítmica y Paleografía, Declamación y Dirección, realización y presentación teatrales.

El Plan de estudios de 1966 se inicia cuando la publicación en el BOE (24 de octubre) del Decreto 2816/1966, estando vigente desde 13 de noviembre de 1966 hasta 1990 con la implantación de la LOGSE. Entre sus principales disposiciones hay que destacar que las enseñanzas de los Conservatorios de Música, estatales y no estatales, tendrían validez académica oficial; estando los estatales subvencionados por el Estado y contarían con profesores funcionarios. Las enseñanzas se dividían por cursos y grados, durando los estudios de Canto ocho cursos: tres de elemental, tres de medio y dos de superior.

Dentro de esta regulación, a los alumnos de Canto e Instrumentos se les exigía tener aprobado el curso de igual orden numérico de Solfeo y Teoría de la Música (aprobar la asignatura troncal al tiempo que las teórico-prácticas). Esta Ley puso de manifiesto que los Conservatorios debían introducir cursos preparatorios de Canto Coral para acrecentar el interés y motivación del alumnado por el canto, con repertorios de obras sencillas y canciones de compositores relevantes a dos y tres voces.

En cuanto a los Diplomas y Títulos expedidos por los Conservatorios oficiales destacaba el Diploma de Enseñanzas Elementales (todos los Conservatorios), Diploma de Instrumentista o Cantante, Título de Profesor de Canto (Conservatorios Profesionales y Superiores), Título de Profesor Superior de Canto (Conservatorios Superiores). Además, eran precisos otros requisitos: Certificado de Estudios Primarios para Diploma Elemental, de Instrumentista o de 
Cantante; el Bachiller Elemental, para Título de Profesor; Bachillerato Superior, Perito o Maestro, para Profesor Superior.

El caso del diploma de Cantante era singular pues, además de cumplir con los requisitos comunes, exigía haber superado dos cursos de Armonía (analítica o armonía y melodía acompañada) un curso teórico-analítico de Formas Musicales y un curso cíclico de Estética e Historia de la Música, de la Cultura y del Arte. Y para obtener el Título de Profesor de Canto era necesario poseer el Diploma Elemental de Canto y aprobar los cursos y asignaturas del grado medio de Canto. El Título de Profesor Superior de Canto se obtenía tras superar el grado anterior, defender conocimientos lingüísticos de italiano, alemán y francés y haber superado las siguientes asignaturas: 6ำ curso de Piano; un curso de Repentización y Transposición Instrumental; dos cursos del Grado Superior de Canto; 2º curso de Estética e Historia de la Música, de la Cultura y del Arte; un curso de Pedagogía especializada; dos cursos de Prácticas de Profesorado.

Otro hito importante en la historia del Canto en España fue la creación, en 1970, de la Escuela Superior de Canto de Madrid, único centro público estatal especializado en la formación de Cantantes Líricos Profesionales. El Decreto 313/1970 del 29 de enero decía que la Escuela era un centro de especialización en música vocal, y de formación relativa a música, cultura e interpretación para futuros cantantes de ópera. La regulación de los estudios de Canto en la Escuela Superior de Madrid se estableció por el Decreto 313/1970 y la Orden de 23 de octubre de 1970, recogiendo la Ordenación del Diploma de Cantante de Conjunto Coral, Diploma de Cantante de Ópera y Diploma Superior de Especialización para Solistas.

El plan de estudios que propone este Decreto de 1970 para un cantante de ópera, establece como asignaturas obligatorias cuatro cursos de: Solfeo y Teoría de la Música, de Técnica del Canto y Repertorio, de Nociones de Piano y Acompañamiento, de Concertación, de Idiomas italiano y alemán, hablados y cantados, de Fonética francesa e inglesa, de Complementos de Cultura general, de Historia aplicada de la Cultura y del Arte. Y dos cursos de Historia 
general de la Música, Historia de la Música Vocal y de la Ópera, Caracterización y Vestuario, Prácticas de Escena e Interpretación. Más cuatro cursos de Nociones y prácticas de Gimnasia rítmica, Esgrima (alumnos) y Ballet (alumnas). Por otro lado, los estudios de Solista especializado (primeras figuras), ampliación de los de Cantante de Ópera, comprenderán dos cursos de Solfeo y Teoría de la Música, Técnica del Canto y Repertorio, Análisis de Obras, Teoría y práctica de Dirección, Interpretación y Arte Escénico, Idiomas Italiano, Francés, Alemán o Inglés, hablados y cantados, Introducción al Folklore, Acompañamiento de Piano, Clases de Conjunto de Música Vocal. Y un curso de Formas Musicales y otro de Armonía elemental.

El Decreto de 1970 ofrecía, y casi obligaba, a los alumnos a asistir a las diferentes conferencias, conciertos y demás actividades públicas que fuesen organizadas por la Escuela Superior de Canto, dándoles la posibilidad de participar en las representaciones de ópera que les fuesen designadas. En cuanto al ingreso en la Escuela, se realizaban unas pruebas de nivel. Los alumnos de Canto de los Conservatorios oficiales de Música podían presentarse a las pruebas si cumplían con la edad establecida y poseían la titulación de cultura general. Si se deseaba continuar los estudios y obtener el Título de Solista Especializado, era obligatorio superar los estudios de Cantante de Ópera. El Diploma de Cantante de Ópera habilitaba para actuar en compañías operísticas o de Teatro Lírico mientras que el Diploma Superior de Especialización para Solistas, habilitaba para interpretar primeras figuras de ópera.

Actualmente, la Escuela Superior de Canto de Madrid (ESCM) es un centro público que depende de la Dirección General de Universidades y Enseñanzas Artísticas Superiores de la Comunidad de Madrid. Su actual plan de estudios (LOE) queda establecido por el Decreto 36/2010, donde se dice que imparte las enseñanzas propias del Título Superior de Música dentro de la especialidad de Interpretación, Itinerario D-Canto. Cumple con el Espacio Europeo de Enseñanzas Superiores al distribuir 240 Créditos ECTS en cuatro cursos, y proporcionar el Nivel 2 MECES. Las múltiples asignaturas 
se agrupan en siete grandes bloques: Cultura, Pensamiento e Historia; Lenguajes y Técnicas de la Música; Instrumento/Voz; Formación instrumental complementaria; Concertación; Asignaturas Optativas y Trabajo de Fin de Grado (https://escm.es).

\section{METODOLOGÍA}

Para conocer a las intérpretes soprano de Albacete durante la segunda mitad del siglo XX se ha realizado una revisión bibliográfica para encuadrar el estudio, completado por entrevistas y cuestionarios individuales creados ad hoc.

El prisma científico de la historia abarca las relaciones coordinadas y subordinadas entre las personas y el motivo por el que han desarrollado sus vidas. Esta idea está conectada con lo cualitativo porque el interés se centra en las cualidades, pensamientos e ideas de las personas, suscitando un interés por mantener vivo el pasado, rescatando la cultura, los ritos, los anhelos (Hernández, Pérez y Trujillo, 2018).

La historiografía histórica estudia y analiza grandes hechos, personajes, procesos y acontecimientos. Pero era necesario encontrar un método que interpretase la pequeña realidad cotidiana, con nuevos puntos de vista que aglutinasen lo geográfico, lo social, lo cultural y lo antropológico. Así surgió la microhistoria, tendencia aparecida en la década de los 70 del siglo $\mathrm{XX}$, una valiosa herramienta destinada al «estudio concreto de los sucesos individuales, encuadrados y relacionados con su contexto. Esta atención a lo pequeño ha confluido, además, con un desplazamiento del punto de interés, desde el "centro" a la" periferia", con gran desarrollo de estudios locales» (Suárez, 2018, p. 28).

En la presente investigación, se ha utilizado la citada microhistoria para dar respuesta a la necesidad de crear un nuevo marco narrativo donde los hechos particulares tuviesen la misma importancia y validez que los generalizadores y deductivos. Es decir, que de acontecimientos personales se pudiera crear una historia completa 
concediendo protagonismo a los sujetos que formaban parte de ella. Así, la microhistoria investiga de abajo hacia arriba, de lo concreto a lo general (Ronen, 2013).

La microhistoria se planteó como una respuesta a la crisis del estructuralismo y el materialismo marxista. Se presentó así como una reacción frente a un cierto estado de la historia social dominante. Una historia supuestamente 'social' pero que quedaba fuertemente anclada en parámetros estructurales, privilegiando la caracterización de 'sistemas' y dejando un minúsculo margen al accionar concreto de los sujetos en tanto actores sociales (p.179).

Por tanto, se han analizado historias personales concretas (vidas de las sopranos), acontecimientos (legislación de los planes de estudio de Canto) y sucesos históricos (desarrollo del Canto en los Conservatorios; devenir del canto lírico en el desarrollo cultural de Albacete). Esta investigación de historias y sus contextos, propia de la microhistoria (Arias, 2014), ha llevado a observar a los personajes de Albacete, protagonistas de la historia recobrada, para observar las relaciones entre ciudad y sopranos, motores del desarrollo musical.

Además, se ha aplicado un enfoque cualitativo, entendido como una vía de investigar sin mediciones numéricas, tomando encuestas, entrevistas, descripciones, puntos de vista de los investigadores, reconstrucciones de los hechos, no tomando en general la prueba de hipótesis como algo necesario (Cortes y León, 2004, p. 10). Este tipo de metodología es el más frecuente en ciencias sociales ya que considera los hechos en su totalidad, por lo que también se denomina holístico (Hernández, 2009; Cotán, 2012; Pérez, Orozco, Trujillo, 2019).

El instrumento de investigación utilizado ha sido la entrevista, muy utilizada en las investigaciones humanísticas. Ésta se basa en la extracción de datos que son tangibles y demostrables aunque pueden darse ciertos errores típicos, siendo los más frecuentes aquellos referidos al muestreo, donde algunas personas son excluidas de la muestra por exigencias de la entrevista; a la cobertura, por- 
que los participantes que cumplen con el patrón ideal del estudio; a la no respuesta, cuando los entrevistados no participan o lo hacen parcialmente; a la medición, por no obtenerse los datos deseados por una mala praxis de la entrevista, porque el entrevistador no la explica o no la realiza con objetividad, o porque el entrevistado no responde con veracidad por respetos humanos, falta de memoria $\mathrm{u}$ otras razones (Casas, Repullo y Donado, 2003).

Las preguntas elaboradas se han dirigido a conocer la trayectoria y vida profesional de cantantes soprano, originarias o asentadas en Albacete, cooperadoras de diferentes maneras al desarrollo musical de la ciudad, que han configurado la población muestral de este trabajo. Recordemos que la muestra está formada por un grupo que pertenece al mismo campo y que constituye un universo de estudio (Arias-Gómez, Villasís-Keever y Miranda Novales, 2016). Los tres tipos de entrevista, personal, telefónica o por correo (Cea D’Ancona, 1996), se han amoldado a la disponibilidad de las encuestadas, garantizando la adecuación a los objetivos de la investigación. Gracias a la entrevista se ha recabado una información precisa y verídica, en complemento a la documentación escrita (escasa e insuficiente). Así, la microhistoria o relato de vida han hecho de la entrevista y la conversación una historia viva (Chárriez, 2012).

En el diseño de la entrevista se han concretado unos interrogantes de investigación:

Para qué, destinada al objetivo: conocer cómo ha influido la voz femenina, las sopranos cantantes (mujeres) en el desarrollo músico-cultural de la ciudad de Albacete.

- $\quad$ Cómo, en base al procedimiento metodológico: gracias a un total de 20 preguntas que configuran la entrevista. - $\quad$ Por qué, para la justificación del trabajo: conocer aspectos básicos del desarrollo musical de Albacete, a través del Conservatorio de la Diputación en la especialidad de Canto y querer difundir los resultados obtenidos además de reconocer el mérito de los agentes implicados. 
Las entrevistas individuales han buscado recopilar datos sobre la formación académica recibida, la trayectoria de sus carreras profesionales, los diferentes ámbitos profesionales por los que se han decantado: interpretación, docencia, sector privado o público, las experiencias individuales que cada soprano ha tenido en su carrera, los repertorios vocales preferidos y los que más han desarrollado, las figuras, interpretativas o pedagógicas, que han sido modelos a seguir, las funciones, logros, reconocimientos, premios, actuaciones, publicaciones y otros méritos importantes obtenidos a lo largo de su vida, la vida y trayectoria musical de la ciudad de Albacete en su historia reciente.

Todo el proceso se realizó en el primer semestre del año 2019. Hubo una primera toma de contacto individual, telefónica o por correo electrónico, para solicitar la colaboración y explicar los objetivos de la investigación. Tras el consentimiento, se establecieron dos fases de recogida de datos: una, para entregar las entrevistas por escrito para las sopranos pudieran preparar con tranquilidad sus respuestas. La segunda, para la realización formal de la entrevista, cara a cara, vía telefónica o por correo electrónico. Los temas abordados en dichas charlas o entrevistas han estado relacionados con la vida de las entrevistadas, con referencias directas a su formación académica y otros estudios posteriores, las trayectorias profesionales emprendidas y el desarrollo de la vida laboral de cada una de ellas. Y para mayor comodidad de las entrevistadas, se concentró toda la información en veinte preguntas.

El tiempo dedicado a los encuentros con cada soprano ha sido variable; no se ha escatimado pero se ha evitado molestar o añadir un trabajo extra a las encuestadas. La intención ha sido que se sintieran cómodas, en un clima agradable, donde disfrutar con cada viaje personal al pasado, respetando por igual la profusión de información o las respuestas directas y concisas. En cualquier caso, existe un reconocimiento a todas y cada una de ellas por su buena disposición y por su participación en esta investigación dedicada a rescatar del olvido aquellos aspectos que, por su directo toque humano, no figuran en las escasas fuentes escritas. 
Las entrevistas personales, parte principal del presente trabajo, revelan valiosa información demostrando que los diferentes rumbos de las carreras profesionales de las sopranos a lo largo de los años. Algunas de ellas han tenido épocas en las que se han dedicado exclusivamente a la docencia mientras que en otras ha primado la interpretación. Es destacable que todas han terminado dedicadas a la enseñanza musical, en diferentes ámbitos y centros educativos. Asimismo, todas coinciden en que el principal motivo que las ha impulsado a desarrollar este desempeño profesional ha sido el querer transmitir los conocimientos y experiencias adquiridos. Todas iniciaron sus estudios musicales en el Conservatorio de Música de Albacete, principal elemento de configuración de la muestra y, casi unánimemente, en el plan de estudios de 1966,

En la siguiente tabla, aparecen detalladas las personas entrevistadas, junto con la fecha de realización de la entrevista. Se han ordenado cronológicamente, siguiendo la edad de la entrevistada, de mayor a menor:

\begin{tabular}{|l|l|l|l|}
\hline Nombre & Edad & Fecha de entrevista & Tipo de entrevista \\
\hline Maribel Martínez & 81 & $15 / 05 / 2019$ & Personal \\
\hline Llanitos Pérez & 76 & $15 / 06 / 2019$ & Personal \\
\hline Elisa Belmonte & Ns/nc & $05 / 06 / 2019$ & Telefónica, por correo \\
\hline Gloria Doñate & Ns/nc & $20 / 04 / 2019$ & Telefónica, por correo \\
\hline Ana Luisa Espinosa & 53 & $4 / 05 / 2019$ & Por correo, personal \\
\hline María Dolores Sanz & 49 & $5 / 05 / 2019$ & Por correo \\
\hline Fuensanta Morcillo & 43 & $14 / 05 / 2019$ & Por correo, personal \\
\hline
\end{tabular}

\section{RESULTADOS}

Para clarificar y poner de relieve los aspectos más importantes de cada trayectoria, se han condensado los datos y aspectos más destacables de cada entrevista para presentarlos, de forma resumi- 
da, en unas tablas personalizadas más adelante. En Anexos quedan recogidas, también de forma resumida, las entrevistas realizadas.

Si nos fijamos en las dos sopranos mayores, María Isabel y Llanitos, observamos que ninguna tuvo una carrera internacional, apenas nacional. Ambas se centraron en la enseñanza, en enseñanza Secundaria y en el Conservatorio, respectivamente. En el caso de María Isabel, sus interpretaciones casi siempre fueron en coros, en gran parte, vinculados a la Sección Femenina. Ha actuado como solista pero en recitales líricos. Sus preferencias se centran en la canción española y la música coral. Llanitos sí interpretó papeles completos y, tras revisar los programas de sus actuaciones, se observan más recitales líricos (canciones, arias de ópera y romanzas de zarzuelas) que producciones musicales de gran formato. Algo muy destacable en ambas son los esfuerzos y trabajos en pro de la educación musical, con abundantes cursos impartidos, algo que las mantuvo en contacto con las técnicas de enseñanza y los métodos de aprendizaje musicales. Además, Llanitos tuvo gran actividad como conferenciante, enseñando durante veinte años, a maestros y profesores, a cuidar adecuadamente sus voces.

Elisa Belmonte es docente en la Escuela Superior de Canto. Fue la primera de las sopranos en salir de Albacete para desarrollar su carrera profesional como intérprete, a nivel nacional e internacional, con numerosos viajes y actuaciones en prestigiosas salas de concierto. También tiene un perfil investigador, con publicaciones de artículos y libros, imparte conferencias sobre la voz humana y el canto y ha participado en el reparto de películas y grabaciones.

Analuisa pertenece a la siguiente década, siendo la primera en estudiar Canto fuera de España en una prestigiosa escuela. Ganadora en múltiples concursos y premios de reconocimiento nacional e internacional, fue la primera de la muestra en ser jurado en concursos internacionales. Desarrolló la crítica musical periodística y ha sido la única que tuvo su propio programa de radio «Do-Fa Radio, Voz y Salud». Actualmente es profesora del conservatorio «Torrejón y Velasco» de canto, coro, historia de la música. 
María Gloria y María Dolores centraron su vida laboral en la docencia. Su perfil performativo se ha centrado en actuaciones corales aunque también han tenido actuaciones como solistas. Gloria es profesora del Conservatorio de la Diputación y ha dirigido varios coros de niños y adultos. Estudió canto por querer desarrollar esta habilidad y porque la hacía feliz. Fue la que desarrolló la primera iniciativa en un proyecto empresarial. Por su parte, María Dolores estudió canto por la satisfacción y disfrute que éste le procuraba en su desarrollo personal ya que siempre había cantado en coros, gracias a su padre, catedrático de Música. Sus trabajos de dirección de coros en Aula Coral le permiten utilizar el canto para dar lo mejor de sí a los más pequeños. Como maestra de Educación Primaria, especialista de música, transmite conocimientos y valores sociales en esta asignatura a través del trabajo en equipo.

Fuensanta condensa varias de las actividades desarrolladas por el resto: estudió en el conservatorio de Albacete, cantó en un coro provincial, estudió fuera de España, ha cantado en varios escenarios internacionales, ha sido miembro de diversos jurados y actualmente es profesora de canto en el Conservatorio de la Diputación. Llevada por el afán de dinamizarla vida musical de Albacete y sus músicos creó la productora «Cachivaches», dando protagonismo a jóvenes músicos y a sus alumnos ante el público.

Las siguientes tablas proporcionan, de manera resumida y de fácil lectura, toda la información obtenida de las entrevistas realizadas sobre la formación académica, la actividad profesional, la escuela de canto y los repertorios trabajados por las sopranos. 


\section{María Isabel Martínez Martínez}

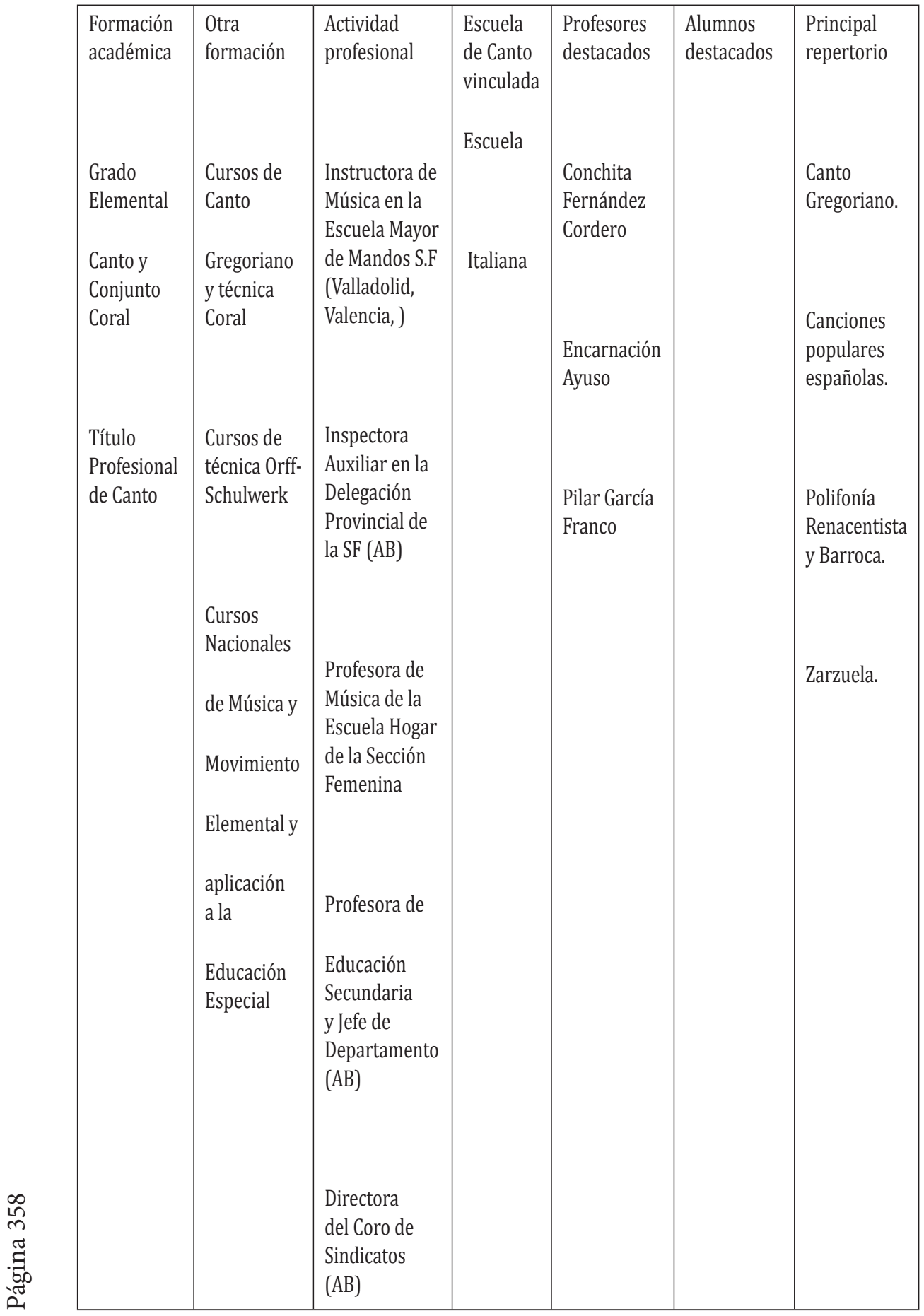




\section{María de los Llanos Pérez Raya}

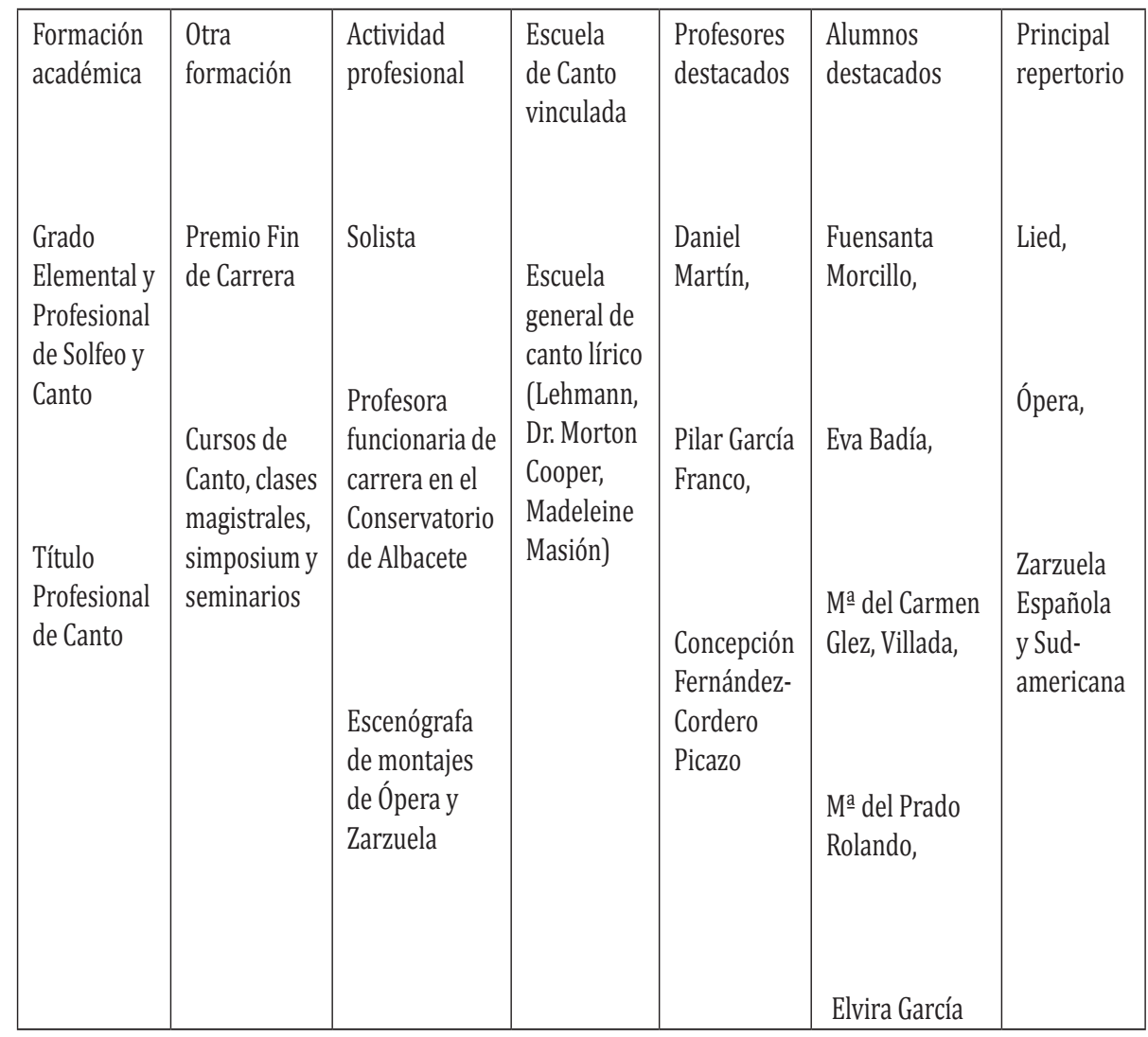




\section{Elisa Belmonte Useros}

\begin{tabular}{|c|c|c|c|c|c|c|}
\hline $\begin{array}{l}\text { Formación } \\
\text { académica }\end{array}$ & Otra formación & $\begin{array}{l}\text { Actividad } \\
\text { profesional }\end{array}$ & $\begin{array}{l}\text { Escuela } \\
\text { de Canto } \\
\text { vinculada }\end{array}$ & $\begin{array}{l}\text { Profesores } \\
\text { destacados }\end{array}$ & \begin{tabular}{|l|} 
Alumnos \\
destacados
\end{tabular} & $\begin{array}{l}\text { Principal } \\
\text { repertorio }\end{array}$ \\
\hline $\begin{array}{l}\text { Diploma de } \\
\text { Cantante de } \\
\text { Ópera. } \\
\\
\text { Título } \\
\text { Superior de } \\
\text { Cantante } \\
\text { Especializada. }\end{array}$ & $\begin{array}{l}\text { Filosofía y } \\
\text { Ciencias de la } \\
\text { Educación. } \\
\text { Doctora. } \\
\text { Título } \\
\text { Profesional } \\
\text { de Solfeo y de } \\
\text { Música }\end{array}$ & $\begin{array}{l}\text { Actriz, } \\
\text { cantante, } \\
\text { profesora. }\end{array}$ & $\begin{array}{l}\text { Escuela } \\
\text { Española. }\end{array}$ & 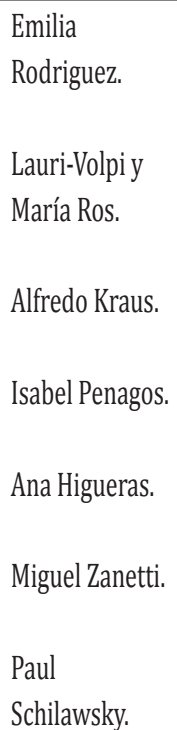 & $\begin{array}{l}\text { Muchos: } \\
\text { solistas en } \\
\text { Españay } \\
\text { extranjero. } \\
\text { Cantantes } \\
\text { del coro de } \\
\text { la Zarzuela, } \\
\text { del Real, } \\
\text { del } \\
\text { Nacional y } \\
\text { TRVE. }\end{array}$ & $\begin{array}{l}\text { Canción } \\
\text { Española. } \\
\text { Zarzuela. }\end{array}$ \\
\hline $\begin{array}{l}\text { Actividades } \\
\text { destacadas }\end{array}$ & $\begin{array}{l}\text { Concursos y } \\
\text { premios }\end{array}$ & $\begin{array}{l}\text { Jurado en } \\
\text { tribunales }\end{array}$ & Publicaciones & Composiciones & $\begin{array}{l}\text { Cantantes } \\
\text { favoritas }\end{array}$ & $\begin{array}{l}\text { Música } \\
\text { favorita }\end{array}$ \\
\hline $\begin{array}{l}\text { Actriz en } \\
\text { tres películas } \\
\text { españolas. } \\
\text { Cantante en } \\
\text { reputadas } \\
\text { sedes } \\
\text { mundiales. } \\
\text { Cantante en } \\
\text { importantes } \\
\text { salas y } \\
\text { teatros. }\end{array}$ & $\begin{array}{l}\text { Verdadera } \\
\text { Dulcinea, } \\
\text { Dulcinea } \\
\text { Universal, Rosa } \\
\text { del Azafrán, } \\
\text { Premio Jacinto } \\
\text { Guerrero. }\end{array}$ & $\begin{array}{l}\text { ESCM, IEA, } \\
\text { Concurso } \\
\text { de } \\
\text { Quintanar } \\
\text { de la Orden. }\end{array}$ & \begin{tabular}{|l} 
In \\
Memoriam, \\
Carmina \\
Useros \\
$(2017)$ \\
\\
Canto. Bases \\
y Método \\
(2018)
\end{tabular} & Ninguna. & $\begin{array}{l}\text { T. Berganza } \\
\text { A. Airteta } \\
\text { Joice } \\
\text { Didonato } \\
\text { Anna } \\
\text { Netrebko } \\
\text { Elina } \\
\text { Garanca }\end{array}$ & $\begin{array}{l}\text { Música } \\
\text { clásica, } \\
\text { coral, vocal, } \\
\text { conciertos } \\
\text { para piano. }\end{array}$ \\
\hline
\end{tabular}




\section{María Gloria Doñate Alcantud}

\begin{tabular}{|c|c|c|c|c|c|c|}
\hline $\begin{array}{l}\text { Formación } \\
\text { académica }\end{array}$ & $\begin{array}{l}\text { Otra } \\
\text { formación }\end{array}$ & $\begin{array}{l}\text { Actividad } \\
\text { profesional }\end{array}$ & $\begin{array}{l}\text { Escuela } \\
\text { de Canto } \\
\text { vinculada }\end{array}$ & $\begin{array}{l}\text { Profesores } \\
\text { destacados }\end{array}$ & $\begin{array}{l}\text { Alumnos } \\
\text { destacados }\end{array}$ & $\begin{array}{l}\text { Principal } \\
\text { repertorio }\end{array}$ \\
\hline $\begin{array}{l}\text { Título } \\
\text { Superior } \\
\text { de Piano, } \\
\text { Solfeo y } \\
\text { Teoría de la } \\
\text { Danza. } \\
\text { Grado } \\
\text { Medio de } \\
\text { Canto. }\end{array}$ & $\begin{array}{l}\text { Título de } \\
\text { Grado } \\
\text { Medio } \\
\text { de Danza } \\
\text { Española. }\end{array}$ & $\begin{array}{l}\text { Cantante, } \\
\text { Profesora, } \\
\text { empresaria. }\end{array}$ & $\begin{array}{l}\text { Escuela } \\
\text { Italiana. }\end{array}$ & $\begin{array}{l}\text { Salvador } \\
\text { Seguí, Ana } \\
\text { Luisa Chova, } \\
\text { Gloria Fabuel, } \\
\text { Fuensanta } \\
\text { Morcillo. }\end{array}$ & $\begin{array}{l}\text { José Javier } \\
\text { Ruiz Sáez, } \\
\text { María del } \\
\text { Valle Robles } \\
\text { de Moya. }\end{array}$ & $\begin{array}{l}\text { Ópera } \\
\text { italiana, } \\
\text { Zarzuela, } \\
\text { Canción } \\
\text { Española. }\end{array}$ \\
\hline $\begin{array}{l}\text { Actividades } \\
\text { destacadas }\end{array}$ & $\begin{array}{l}\text { Concursos } \\
\text { y premios }\end{array}$ & $\begin{array}{l}\text { Jurado en } \\
\text { tribunales }\end{array}$ & Publicaciones & Composiciones & $\begin{array}{l}\text { Cantantes } \\
\text { favoritas }\end{array}$ & $\begin{array}{l}\text { Música } \\
\text { favorita }\end{array}$ \\
\hline $\begin{array}{l}\text { Alma Mater } \\
\text { del «Aula } \\
\text { Coral»: } \\
\text { Empresaria } \\
\text { «G.D. } \\
\text { Bodas»: }\end{array}$ & $\begin{array}{l}\text { Pregonera } \\
\text { de la } \\
\text { Feria de } \\
\text { Albacete } \\
\text { de } 2019 .\end{array}$ & $\begin{array}{l}\text { Jurado de } \\
\text { tribunal del } \\
\text { Conservatorio } \\
\text { de la Excma. } \\
\text { Diputación de } \\
\text { Albacete. }\end{array}$ & $\mathrm{x}$ & $x$ & $\begin{array}{l}\text { Teresa } \\
\text { Berganza, } \\
\text { Ahinoa } \\
\text { Arteta, } \\
\text { Netrebko, } \\
\text { Garanca, } \\
\text { Didonato. }\end{array}$ & $\begin{array}{l}\text { Música } \\
\text { clásica, } \\
\text { coral, } \\
\text { vocal, } \\
\text { conciertos } \\
\text { sinfónicos. } \\
\text { ¿?? }\end{array}$ \\
\hline
\end{tabular}




\section{Ana Luisa Sánchez Espinosa}

\begin{tabular}{|c|c|c|c|c|c|c|}
\hline $\begin{array}{l}\text { Formación } \\
\text { académica }\end{array}$ & $\begin{array}{l}\text { Otra } \\
\text { formación }\end{array}$ & $\begin{array}{l}\text { Actividad } \\
\text { profesional }\end{array}$ & $\begin{array}{l}\text { Escuela } \\
\text { de Canto } \\
\text { vinculada }\end{array}$ & $\begin{array}{l}\text { Profesores } \\
\text { destacados }\end{array}$ & $\begin{array}{l}\text { Alumnos } \\
\text { destacados }\end{array}$ & $\begin{array}{l}\text { Principal } \\
\text { repertorio }\end{array}$ \\
\hline $\begin{array}{l}\text { Título de } \\
\text { Profesor de } \\
\text { Canto. } \\
\text { Estudió en } \\
\text { Fondation } \\
\text { Royaumont. }\end{array}$ & $\begin{array}{l}\text { Título de } \\
\text { Magisterio. } \\
\\
\text { Licenciada } \\
\text { en Historia y } \\
\text { Ciencias de } \\
\text { la Música. }\end{array}$ & $\begin{array}{l}\text { Cantante, } \\
\text { profesora. }\end{array}$ & $\begin{array}{l}\text { Escuela } \\
\text { Italiana. }\end{array}$ & $\begin{array}{l}\text { Daniel Ferro. } \\
\text { Lorraine } \\
\text { Nubar. }\end{array}$ & NS/NC. & $\begin{array}{l}\text { Ópera } \\
\text { francesa, } \\
\text { italiana. } \\
\text { Mèlodie } \\
\text { Française, } \\
\text { Repertorio } \\
\text { de Concierto } \\
\text { Español, } \\
\text { Ibero- } \\
\text { americano y } \\
\text { Zarzuela. }\end{array}$ \\
\hline $\begin{array}{l}\text { Actividades } \\
\text { destacadas }\end{array}$ & $\begin{array}{l}\text { Concursos y } \\
\text { premios }\end{array}$ & $\begin{array}{l}\text { Jurado en } \\
\text { tribunales }\end{array}$ & Publicaciones & Composiciones & $\begin{array}{l}\text { Cantantes } \\
\text { favoritas }\end{array}$ & $\begin{array}{l}\text { Música } \\
\text { favorita }\end{array}$ \\
\hline $\begin{array}{l}\text { Creadora } \\
\text { de «Voz } \\
\text { y Salud», } \\
\text { cantante en } \\
\text { numerosos } \\
\text { teatros y } \\
\text { salas del } \\
\text { mundo. } \\
\text { También } \\
\text { numerosas } \\
\text { apariciones } \\
\text { en radio } \\
\text { y TV. }\end{array}$ & $\begin{array}{l}\text { Francisco } \\
\text { Alonso, } \\
\text { Eva Duarte } \\
\text { de Perón, } \\
\text { Canto de } \\
\text { Logroño, } \\
\text { Jean } \\
\text { Giraudeau, } \\
\text { María } \\
\text { Malibrán, } \\
\text { La voz de } \\
\text { Rusia, Mujer } \\
\text { destacada } \\
\text { de AB. }\end{array}$ & $\begin{array}{l}\text { Concurso } \\
\text { Internacional } \\
\text { de Habaneras } \\
\text { y Polifonía de } \\
\text { Torrevieja } \\
\text { Concurso } \\
\text { de Canto de } \\
\text { Abarán. }\end{array}$ & $\begin{array}{l}\text { Numerosos } \\
\text { artículos } \\
\text { en «La } \\
\text { Encomienda } \\
\text { de Castilla»y } \\
\text { «La Tribuna } \\
\text { de Albacete». }\end{array}$ & & $\begin{array}{l}\text { E. } \\
\text { Gruverova, } \\
\text { Pilar } \\
\text { Lorengar, } \\
\text { Reneé } \\
\text { Fleming. }\end{array}$ & $\begin{array}{l}\text { Música } \\
\text { clásica, } \\
\text { coral, vocal, } \\
\text { conciertos } \\
\text { sinfónicos. }\end{array}$ \\
\hline
\end{tabular}




\section{María Fuensanta Morcillo Zafra}

\begin{tabular}{|c|c|c|c|c|c|c|}
\hline $\begin{array}{l}\text { Formación } \\
\text { académica }\end{array}$ & $\begin{array}{l}\text { Otra } \\
\text { formación }\end{array}$ & $\begin{array}{l}\text { Actividad } \\
\text { profesional }\end{array}$ & $\begin{array}{l}\text { Escuela } \\
\text { de Canto } \\
\text { vinculada }\end{array}$ & $\begin{array}{l}\text { Profesores } \\
\text { destacados }\end{array}$ & $\begin{array}{l}\text { Alumnos } \\
\text { destacados }\end{array}$ & $\begin{array}{l}\text { Principal } \\
\text { repertorio }\end{array}$ \\
\hline $\begin{array}{l}\text { Título } \\
\text { Profesional de } \\
\text { Canto. } \\
\text { Título Superior } \\
\text { de Canto. }\end{array}$ & $\begin{array}{l}\text { Título de } \\
\text { Danza } \\
\text { Clásica. }\end{array}$ & $\begin{array}{l}\text { Cantante, } \\
\text { profesora de } \\
\text { canto. }\end{array}$ & $\begin{array}{l}\text { Italiana, } \\
\text { Americana. }\end{array}$ & $\begin{array}{l}\text { Llanitos Pérez } \\
\text { Raya, Aída } \\
\text { Monasterio, } \\
\text { Celsa Tamayo, } \\
\text { Virginia } \\
\text { Zeani, Suso } \\
\text { Mariátegui, } \\
\text { Raúl Jiménez, } \\
\text { Ana Luisa } \\
\text { Chova, V. de los } \\
\text { Ángeles. }\end{array}$ & $\begin{array}{l}\text { María } \\
\text { del Valle } \\
\text { Robles de } \\
\text { Moya, José } \\
\text { Javier Sáez } \\
\text { Ruiz, Elena } \\
\text { Fernández, }\end{array}$ & $\begin{array}{l}\text { Ópera, } \\
\text { Zarzuela. }\end{array}$ \\
\hline $\begin{array}{l}\text { Actividades } \\
\text { destacadas }\end{array}$ & $\begin{array}{l}\text { Concursos } \\
\text { y premios }\end{array}$ & $\begin{array}{l}\text { Jurado en } \\
\text { tribunales }\end{array}$ & Publicaciones & Composiciones & $\begin{array}{l}\text { Cantantes } \\
\text { favoritas }\end{array}$ & $\begin{array}{l}\text { Música } \\
\text { favorita }\end{array}$ \\
\hline $\begin{array}{l}\text { Cantante en } \\
\text { numerosas } \\
\text { salas y teatros } \\
\text { del mundo. }\end{array}$ & $\begin{array}{l}\text { Finalista } \\
\text { en el } \\
\text { Concurso } \\
\text { Aussensi, } \\
\text { el de las } \\
\text { Palmas, el } \\
\text { de Sevilla... }\end{array}$ & $\begin{array}{l}\text { Tribunales del } \\
\text { Conservatorio } \\
\\
\text { Jurado del «I } \\
\text { Concurso de } \\
\text { Canto Lírico } \\
\text { Nacional de } \\
\text { Albacete». }\end{array}$ & & & $\begin{array}{l}\text { Maria } \\
\text { Callas, Kiri } \\
\text { te Kanawa, } \\
\text { Lucia Pop, } \\
\text { Victoria } \\
\text { de los } \\
\text { Ángeles, } \\
\text { Pilar } \\
\text { Lorengar. }\end{array}$ & $\begin{array}{l}\text { Música } \\
\text { clásica } \\
\text { vocal. }\end{array}$ \\
\hline $\begin{array}{l}\text { Cantante y } \\
\text { fundadora de } \\
\text { la Compañía } \\
\text { Lírica } \\
\text { «Cachivaches». }\end{array}$ & & & & & & \\
\hline $\begin{array}{l}\text { Jurado y } \\
\text { fundadora del } \\
\text { «I Concurso de } \\
\text { Canto Lírico } \\
\text { Nacional de } \\
\text { Albacete». }\end{array}$ & & & & & & \\
\hline
\end{tabular}




\section{María Dolores Sanz Redondo}

\begin{tabular}{|c|c|c|c|c|c|c|}
\hline $\begin{array}{l}\text { Formación } \\
\text { académica }\end{array}$ & $\begin{array}{l}\text { 0tra } \\
\text { formación }\end{array}$ & $\begin{array}{l}\text { Actividad } \\
\text { profesional }\end{array}$ & $\begin{array}{l}\text { Escuela } \\
\text { de Canto } \\
\text { vinculada }\end{array}$ & $\begin{array}{l}\text { Profesores } \\
\text { destacados }\end{array}$ & $\begin{array}{l}\text { Alumnos } \\
\text { destacados }\end{array}$ & $\begin{array}{l}\text { Principal } \\
\text { repertorio }\end{array}$ \\
\hline $\begin{array}{l}\text { Título } \\
\text { Profesional de } \\
\text { Canto. }\end{array}$ & $\begin{array}{l}\text { Diplomada } \\
\text { en } \\
\text { Magisterio. }\end{array}$ & $\begin{array}{l}\text { Directora } \\
\text { de coro, } \\
\text { maestra, } \\
\text { cantante } \\
\text { coral. }\end{array}$ & Ninguna & \begin{tabular}{|l} 
Montserrat \\
Caballé, \\
Renata Scotto, \\
Ana Luisa \\
Chova, José \\
Ferrero, Pilar \\
Jurado, Llanos \\
Pérez Raya, \\
Fuensanta \\
Morcillo.
\end{tabular} & $X$ & $\begin{array}{l}\text { Haendel, } \\
\text { música } \\
\text { barroca, } \\
\text { Ópera y } \\
\text { Zarzuela. }\end{array}$ \\
\hline $\begin{array}{l}\text { Actividades } \\
\text { destacadas }\end{array}$ & $\begin{array}{l}\text { Concursos } \\
\text { y premios }\end{array}$ & $\begin{array}{l}\text { Jurado en } \\
\text { tribunales }\end{array}$ & Publicaciones & Composiciones & $\begin{array}{l}\text { Cantantes } \\
\text { favoritas }\end{array}$ & $\begin{array}{l}\text { Música } \\
\text { favorita }\end{array}$ \\
\hline $\begin{array}{l}\text { Aula Coral } \\
\text { AB, Coro del } \\
\text { Conservatorio } \\
\text { «Tomás de } \\
\text { Torrejón y } \\
\text { Velasco», Coro } \\
\text { «Philomusica } \\
\text { CLM». }\end{array}$ & $\begin{array}{l}\text { Coral de } \\
\text { Albacete } \\
\text { en } \\
\text { Cocentaina } \\
\text { y Griñón }\end{array}$ & & $X$ & $X$ & $\begin{array}{l}\text { V. de lo } \\
\text { Ángeles, } \\
\text { Bayo Rey, } \\
\text { Arteta, } \\
\text { Berganza, } \\
\text { Kiri te } \\
\text { Kanawa, } \\
\text { Ameling, } \\
\text { Norman, } \\
\text { Netrebko, } \\
\text { Bartoli. }\end{array}$ & $\begin{array}{l}\text { Música } \\
\text { clásica } \\
\text { barroca, } \\
\text { música coral, } \\
\text { música } \\
\text { renacentista, } \\
\text { música } \\
\text { folklórica. }\end{array}$ \\
\hline
\end{tabular}




\section{CONCLUSIONES}

La investigación desarrollada ha pretendido construir una intrahistoria de la vida musical de Albacete ante el riesgo de perder en el olvido grandes esfuerzos y pequeños detalles sumamente interesantes. Gracias a la microhistoria y a las historias de vida se ha buscado un objetivo básico: recuperar una faceta del patrimonio cultural local que, al no haber sido estudiado, pudiera parecer que nunca existió o que no tuvo la importancia que revelan los datos recogidos y los análisis realizados (Arias, 2014; Cotán, 2012; Ronen, 2013). El principal problema ha sido la escasa documentación escrita (libros, artículos, referencias en publicaciones colectivas, monografías, biografías, entre otros) para crear una contextualización apoyada en fuentes escritas relacionadas con el objeto principal del estudio: las sopranos que estudiaron en el Conservatorio de la Excma. Diputación Provincial de Albacete en la segunda mitad del siglo XX.

Otro objetivo, más específico, fue el de conocer los diferentes planes de estudio españoles de Canto, en concreto, los de 1942 y 1966 que afectaron a las sopranos de la muestra (Decreto de 15 de junio de 1942; Decreto 2816/1966 de 24 de octubre de 1966). Con ello, se pretendía obtener una visión de la transformación y evolución de la enseñanza musical del canto en los conservatorios desde principios del siglo XX. Y enlazando con esto, surgió la necesidad de valorar la influencia que tuvo el Real Conservatorio de Música y Danza de Albacete en la formación de las citadas sopranos, buscando información sobre la repercusión que tuvieron sus principales actividades en la difusión musical en Albacete. La formación inicial recibida en dicho centro, impartida por Conchita Fernández Cordero, la primera profesora de Canto que tuvo el Conservatorio (Ballesteros, 1992), fue la base que propició que algunas de las sopranos hayan sido figuras reconocidas del mundo musical en diferentes puntos de España y en el extranjero. El Real Conservatorio de Música y Danza de Albacete permitió que varias generaciones de 
jóvenes recibieran una formación musical de calidad, completada con cursos de especialización teórica, coral, interpretativa (Apuntes musicales, s.f., 2011).

La entrevista con cada soprano ha generados diversos espacios humanos proclives a recuerdos y confidencias sobre hechos y personajes destacados en la vida cultural y musical de Albacete durante el pasado siglo. Por discreción y confidencialidad y para mantener el rigor científico del trabajo, se han silenciados las referencias anecdóticas y personales, en la presentación de datos y en las conclusiones. Conocer las historias de vida de aquellas personas que contribuyeron al desarrollo artístico-cultural de la ciudad ayuda a entender la situación actual. Y al rescatar acontecimientos y fragmentos de vidas, para liberar del olvido y la ignorancia un tiempo pasado, ha permitido elaborar una historia.

El estudio de la vida artística y personal de las diferentes sopranos albaceteñas ha demostrado el impacto que tuvo la presencia de la mujer en el panorama artístico, cultural y musical de esta ciudad, derivados de una enseñanza consolidada, con diversas actividades como el desarrollo de la música coral, la creación de un programa de radio, la inauguración y estabilización de una compañía lírica, el establecimiento del Primer Concurso Nacional de Canto Lírico de Albacete, entre otros.

Todas las sopranos tiene en común dos aspectos: haber estudiado en el Real Conservatorio de Música y Danza de Albacete y haber ejercido una influencia directa en los procesos de enseñanza-aprendizaje musicales locales, por haber ejercido la docencia en algún momento de su vida. Por ejemplo, Llanitos y María Isabel sintieron la vocación de enseñar, en el Conservatorio y en Secundaria, lo que no les impidió ser intérpretes en momentos puntuales. Del mismo modo, Gloria y María Dolores también apostaron por la enseñanza: en el Conservatorio Profesional y en un colegio de Primaria, compartiendo el deseo de inculcar la pasión por la música desde edades tempranas. Los casos más diferentes los encontramos en las sopra- 
nos de generaciones intermedias: Elisa (la única que no ha ejercido la docencia Albacete), Analuisa y Fuensanta. Las tres son intérpretes pero la primera de ellas, ha sido escritora e investigadora, obteniendo el título de doctorado; la segunda, musicóloga y periodista; la tercera, empresaria. Las tres han dado vida a su vocación docente en los conservatorios. Teniendo en cuenta estos ejemplos, podemos intuir que la belleza de la enseñanza y el amor por la música están estrechamente vinculados. Su deseo de transmitir su pasión por la voz en la música les ha llevado a mantener su vida laboral como profesoras junto a su carrera interpretativa. A lo que añaden otros aspectos como la creación de concursos musicales, participación en jurados, redacción de prensa, investigación y publicación, creación de empresas o asociaciones, realización de conciertos y recitales, entre otros.

La música lírica ha permitido a la mujer adquirir importancia, visibilidad y reconocimiento en diversos ámbitos, educativos, artísticos y sociales. El éxito femenino, el divismo, adquirido en la lírica está estrechamente ligado a los papeles defendidos en óperas, zarzuelas y canciones de concierto, demostrando su virtuosismo (Peralta, 2018). Con su talento natural y esfuerzo humano, las cantantes lograron que sus trayectorias personales fueran su mejor interpretación artística.

Finalmente, se considera alcanzado el objetivo fundamental de dar a conocer los aspectos vitales y profesionales más relevantes de diferentes sopranos de Albacete que iniciaron su formación en el Conservatorio de la Diputación Provincial. Valga este intento de difundir sus figuras y trayectorias profesionales como reconocimiento a su dedicación musical, hecha vida gracias a la voz, alma inmortal de la música. Recordando las palabras del último caballero, la música cura los sentimientos podridos y alivia los trabajos que nacen del espíritu (De Cervantes, 1605, p. 42).

La música, en su aspecto emocional, conmueve al hombre para perfeccionarlo. El intérprete vocal se olvida de sí mismo y se con- 
vierte en alguien al que se puede comprender o del que aprender, amar, odiar, admirar... Al analizar las trayectorias de las encuestadas, se observa cómo la música las ha acompañado en su recorrido a lo largo de los años, ya que las exigencias de esta disciplina artística las motivaron a dar lo mejor de sí haciendo de sus vidas un arte vivo. 


\section{REFERENCIAS BIBLIOGRÁFICAS}

Albacete. Diario de la tarde. Archivo Histórico Provincial. Carpeta 131; Carpeta 132.

Apuntes Musicales. Revista del Real Conservatorio Profesional de Música y Danza (2011), 5-6. Sin firma. https://studylib.es/ doc/7808702/revista-del-real-conservatorio-profesionalde-m\%C3\%BAsica-y-danza

ARIAS, P. (2014). Microhistoria e historia regional. Desacatos. Revista de Ciencias Sociales,(21),177-186. https://doi. org/10.29340/21.1388

ARIAS-GÓMEZ, J.; Villasís-Keever, M.Á. y Miranda Novales, Måa. G. (2016). El protocolo de investigación III: la población de estudio. Revista Alergia México, 63(2), 201-206.

BALLESTEROS GONZÁLEZ, S. (1992). Historia del Conservatorio de Música de Albacete. Diputación Provincial. Albacete

BORRELL, F. (1912). El wagnerianismo en Madrid. Conferencia leída el 4 de mayo de 1911, en el Teatro de la Princesa, Madrid CALDERÓN ESCOBAR, L. (2017). Los distintos modelos de Enseñanza de la Música hoy en el Estado Español. Música Oral del Sur, Centro de Documentación Musical de Andalucía(14), 227-252. http://www.centrodedocumentacionmusicaldeandalucia.es/export/sites/default/publicaciones/pdfs/ los_distintos_modelos_de_ensenanza_de_la_musica_hoy_en_ el_estado_espanol.pdf

CASAS ANGUITA; REPULLO LABRADORA, J.R. y DONADO CAMPOS, J. (2003). La encuesta como técnica de investigación. Elaboración de cuestionarios y tratamiento estadístico de los datos. Aten Primaria, 31(8), 527-38.

CASARES RODICIO, E. (1995). La música en el siglo XIX español. Conceptos fundamentales. En La música española en el siglo XIX, Casares Rodicio y Alonso González eds. Universidad de Oviedo. 
CEA D’ANCONA, Mà. A. (1996). Metodología cuantitativa: estrategias y técnicas de investigación social. Editorial Síntesis Sociología S.A.

CORTES, M.E. y León, M.I. (2004). Generalidades sobre metodología de la investigación. Colección Material Didáctico.

COTÁN FERNÁNDEZ, A. (2012). Investigación-participación e historias de vida, un mismo camino. En III Jornadas sobre Historias de Vida en Educación, 1-14. https://www.fpce.up.pt/iiijornadashistoriasvida/pdf/2_Investigacion-participacion $\% 20$ e\%20Historias\%20de\%20vida.pdf

CHÁRRIEZ CORDERO, M. (2012). Historias de vida: Una metodología de investigación cualitativa. Revista Griot, 5 (1), 50-67. https://revistas.upr.edu/index.php/griot/article/download/1775/1568

CERVANTES SAAVEDRA, M de. (1605). El ingenioso hidalgo Don Quijote de la Mancha. (Florencio Sevilla, 2014). Alianza Editorial. MOYA MARTÍNEZ DE, Mạ.V. (2013). La música madrileña vista por ella misma (1868-1900). Alfar Universidad.

Diccionario de la Real Academia Española (https://dle.rae.es )

España. Decreto de 15 de junio, sobre organización de los Conservatorios de Música y Declamación. Boletín Oficial del Estado, 15 de junio de 1942, núm. 185, 4.838- 4.840. https:// www.boe.es/datos/pdfs/BOE//1942/185/A04838-04840.pdf

España. Decreto 2816/1966 de 24 de octubre, sobre Reglamentación general de los Conservatorios de Música. Boletín Oficial del Estado, de 24 de octubre de 1966, 13381- 13387. https://www.boe.es/boe/dias/1966/10/24/pdfs/A1338113387.pdf

España. Decreto 36/2010, de 2 de junio, del Consejo de Gobierno sobre el Plan de Estudios para la Comunidad de Madrid, de las enseñanzas artísticas superiores de Grado de Música. Boletín Oficial de la Comunidad de Madrid, 11 de junio de 2011, núm. 141, 11-253. http://www.madrid.org/wleg_pub/secure/normativas/contenidoNormativa.jsf?opcion=VerHtml\&n 
mnorma $=7257$ \#no-back-button

España. Ley de Educación Nacional de 1942

GÓMEZ DE LA SERNA, G. (1976). Gracias y desgracias del Teatro Real. Abreviatura de su historia. Ministerio de Educación y Ciencia. HARO-ALMANSA, R. y van Zummeren-Moreno, G. (2017). Origen y desarrollo de los Conservatorios Superiores de Música españoles. En Actas IV Congreso Nacional y II Congreso Internacional de Conservatorios Superiores de Música: Formación y evaluación en los diferentes niveles de la Educación Musical. Conservatorio Superior de Música de Castilla La Mancha, noviembre, 2017, (pp. 283- 298).

HERNÁNDEZ, K. S. (2009). El método historia de vida: alcances y potencialidades. http://www.gestiopolis.com/economia/ metodo-de-investigacióncualitativa.htm

HERNÁNDEZ OROZCO, G.; Pérez Piñón, F.A.; y Trujillo Holguín, J.A. (2018). Mitos, ritos, utopías, idolatrías, alienación y fetiches de la educación. Debates por la Historia, 6 (1), 193-212. https:// vocero.uach.mx/index.php/debates-por-la-historia/article/ view/13

JULIÁ DÍAZ, S., Ringrose, D., Segura Graíño, C. (1995). Madrid: historia de una capital. Alianza Editorial.

MUÑOZ, M. (1965). Historia del teatro en España. Tesoro

PEÑA Y GOÑI, A. (1881). La ópera española y la música dramática en España en el siglo XIX: apuntes históricos, Imprenta de El Liberal, 1881 (ICCMU, 2004, ed. facs.).

PERALTA, M. (2018). La voz femenina en la ópera. Carácter e interpretación. Huygens Editorial.

PÉREZ PIÑóN, F., Orozco, G., Trujillo Holguín, J. (2019). Universalización de la microhistoria. Debates Por La Historia, 7(1), 197-221. https://vocero.uach.mx/index.php/debates-porla-historia/article/view/109/156

RONEN, M. (2013). La microhistoria como referente teórico- metodológico. Un recorrido por sus vertientes y debates conceptuales. Historia actual online, (30), 167-173. 
SARGET ROS, M. A. (2000). Perspectiva Histórica de la Educación Musical. Ensayos. Revista de la Facultad de Albacete, 15, 117 122.

SOPEÑA IBÁÑEZ, F. (1967). Historia crítica del Conservatorio de Madrid. Ministerio de Educación y Ciencia.

SUÁREZ GARCÍA, J.I. (2018). A modo de introducción: el teatro lírico en la civilización del periódico. En Música lírica y prensa en España (1868-1936): ópera, drama lírico y zarzuela. José Ignacio Suárez García Ramón Sobrino María Encina Cortizo (Editores), Hispanic Music Series, 1. Ediciones Universidad Oviedo, (pp. 13-34). 


\section{ANEXOS}

\section{MARÍA ISABEL MARTÍNEZ MARTÍNEZ}

La música es la unión de muchas individualidades en un todo. Esta cualidad se advierte con especial fuerza en la música coral.

Nuestra primera entrevistada nace en Albacete, el 31 de enero de 1938. Comienza sus estudios de canto animada por su familia, que ve en su carácter, disciplina y musicalidad aptitudes para ser un buen músico, catalogada por su voz en la tesitura de soprano lírica. Desde el año 1956 hasta 1960, cursa los estudios de solfeo, canto, piano y armonía (materias obligadas en el Grado Elemental dentro del Plan de Estudios Reglados de 1942) en el Real Conservatorio de Música y Danza de Albacete. En el curso 1956-57, se presentó a los exámenes del Conservatorio como alumna libre, tras recibir clases particulares de doña Rita. Paso a ser alumna oficial en el curso 1957-58. En 1960 abre un paréntesis en sus estudios y se incorpora a la vida laboral. Retoma los estudios de Canto y Conjunto Coral en 1976 en el Conservatorio de Albacete y en 1978 los finaliza al obtener el Título Profesional de Canto por el Real Conservatorio Superior de Música y Escuela de Arte Dramático y Danza de Murcia, con el Plan de estudios de 1942. Los profesores oficiales que destaca del Conservatorio de Albacete son: Raimundo González (Solfeo), Doña África (Armonía), Conchita Fernández Cordero (Conjunto Coral y Canto). Y en Murcia, la catedrática Encarnación Ayuso (Profesora de Canto). Al hablar de su formación académica, aparte de los estudios musicales en la especialidad de Canto ya mencionados, en los Conservatorios de Albacete y Murcia, se destacan los numerosos cursos de especialización realizados durante casi cuarenta años: desde 1958 a 1997, diversos cursos en Delegación Nacional de la Sección Femenina del Movimiento (Canto Gregoriano y técnica vocal; Curso de Orff - Schulwerk; Curso de Técnicas Musicales); Curso de Metodología Kodaly (Kecskemét, Hungría, 1980); diversos cursos de Pedagogía musical Bachillerato e Historia de la Música (Madrid, Gijón, 
Baeza, Albacete); varios cursos y proyectos educativos del MEC en centros de enseñanzas medias.

Su extensa trayectoria profesional nos muestra a una mujer trabajadora, dinámica, con espíritu de servicio. Nuestra entrevistada es alguien que ha sabido adaptarse en todo momento a los cambios que han ido surgido: políticos, sociales, pedagógicos, los cuales repercutieron en su trayectoria laboral. Se inició muy joven en lo profesional cuando, con poco más de 20 años, comenzó en la docencia en la realización de las Cátedras Ambulantes de la Sección Femenina. Estas Cátedras eran escuelas de formación que iban de pueblo en pueblo o de aldea en aldea (zonas con menos de 5.000 residentes) para proveerles de la educación básica necesaria (leer, escribir, cálculos básicos, cantar) y otros conocimientos especializados (lecciones de agricultura, de cómo cultivar el campo para optimizar su provecho; labores, cuidado de la casa y la familia, nociones de primeros auxilios...). También se enseñaba religión, cocina y gimnasia. Es importante mencionar que las cátedras disponían de un servicio de sanidad (una médico y una enfermera) que revisaban la salud de la población. Aunque las cátedras estaban principalmente destinadas a mujeres y niños, podían acudir a ellas gratuitamente hombres, ancianos y demás habitantes que lo deseasen. Las cátedras solían permanecer en un pueblo entre 45 y 60 días y después marchaban a otro; se solía dejar a una persona encargada en la zona que supervisase la permanencia de todo lo enseñado. Es destacable que las falangistas de la Sección Femenina hacían un estudio de población de los sitios que visitaban: tipo de artesanía, comercio, industria, trajes típicos regionales, romerías, tradiciones, advocaciones, recetas culinarias de la zona, entre otros. «Los bailes, canciones y trajes regionales pasaron a Coros y Danzas, las recetas de cocina fueron recopiladas en un libro que editó la sección femenina, y la artesanía fue rescatada con la creación del servicio de «Ayuda al Hogar» (Rebollo, 205, p. 285). Generalmente, las Cátedras eran grandes caravanas con ruedas, pero Maribel y sus compañeras realizaron sus servicios por la zona de la Manchuela en mula, debido a la pobreza de la 
zona y la escasez de medios y recursos. Maribel guarda duros pero gratos recuerdos de su paso por diferentes pueblos de la provincia, como Ossa de Montiel y otros de la sierra, en unos años en los que los ideales y la juventud se aliaron para trabajar con ilusión

Su buen hacer humano y educativo motivó que sus mandos le ofreciesen una plaza de Instructora de Música en la Escuela Mayor de Mandos «José Antonio» en el Castillo de la Mota, en Medina del Campo (Valladolid), dependiente de la Sección Femenina y de la Secretaría General del Movimiento, desde el 1 de noviembre de 1959 al 31 de diciembre de 1961. Fue una época muy feliz de la que guarda memorias estupendas, de las diversas actividades, del compañerismo y del trato humano con jóvenes de diversas partes de España y de otros países. En esta línea, continuó nuestra soprano su actividad docente, tras finalizar su formación como Profesora de Música en la Escuela de Mandos de la Sección Femenina de Beniferri (Valencia) desde 1961. Durante unos meses, de manera simultánea, fue Inspectora Auxiliar en la Delegación Provincial de la Sección Femenina de Albacete, desde el 1 de marzo al 31 de diciembre de 1962.

Años más tarde, después de haber sido madre de dos hijos, se reincorpora al mundo laboral como profesora de Música de la Escuela Hogar de la Sección Femenina de Albacete, del 1 de octubre de 1967 al 30 de septiembre de 1971, al tiempo que ejercía como Profesora de Música en la Sección Filial no 1 del Instituto Nacional de Enseñanza Media Femenino de Albacete, (actual IES «Bachiller Sabuco») de 1967 a 1972. Durante los años setenta, cultivó una de sus pasiones, la de dirigir grupos corales, siendo Directora del Coro de Sindicatos en Albacete, así como de otras agrupaciones escolares. Maribel cambió de centro de enseñanza y desde el curso 19711972, ocupó la plaza de Música en el Instituto de Enseñanza Media Mixto no 3 «Andrés de Vandelvira», de Albacete, hasta el curso 1989-1990. Entre medias, en 1985, aprueba el Concurso Oposición como Agregado Nacional de Bachillerato, (más tarde, Profesor de Educación Secundaria). En este centro, formó parte del equipo experimental de la reforma educativa, desde el 1 de octubre de 1988 
al 7 de junio de 1989. En el curso 1992-1993 efectúa su traslado al Instituto $\mathrm{n}$ - 6 de Albacete, manteniendo su categoría profesional de Jefe de Seminario de Música (más tarde, Jefe de Departamento).

Desde muy joven, durante la época estival, alternaba un período vacacional con otro laboral, ya que continuaba trabajando en los Albergues juveniles de la Sección Femenina, distinguida como Jefe de Campamento, Albergue y Colonia (1977) por el Ministerio de Cultura, Dirección General de Desarrollo Comunitario (Escuela Superior de Dirigentes Nacional Isabel La Católica» de Navas del Marqués) o siendo también Profesora de Música en los cursos de verano para instructoras (alumnas de Magisterio) en Onteniente (Valencia) y en el Castillo de San Servando (Toledo) durante la década de los setenta.

Maribel fue en su época una adelantada en lo referente a la inserción laboral de la mujer, siendo pionera en actividades destinadas al desarrollo cultural, social e intelectual de zonas deprimidas; Mando de Campamento y Albergue Juvenil femenino en verano; profesora de enseñanzas medias y secundaria en institutos mixtos, directora de coros de infantiles y de adultos, miembro desde sus inicios del conocido Orfeón de la mancha de Albacete. Se entregó a la docencia de la Música, intentando transmitir su amor a la Música y el placer por el canto a los diferentes grupos de personas con los que estuvo relacionada a lo largo de años, en diversos entornos y situaciones, consciente de que ella sólo era una mensajera de la belleza encerrada en el arte musical.

En lo que a trabajos de investigación o publicaciones se refiere, Maribel colaboró en trabajos de recuperación del patrimonio musical y del Folklore regional, formando parte de los Coros y Danzas de Sección Femenina, que como se mencionó anteriormente, se dedicaron a indagar sobre las costumbres y tradiciones locales y plasmarlas por escrito para perpetuarlas. Además de los Coros y Danzas de la S.F, participó en la organización del Orfeón de la Mancha, donde estuvo desde su creación hasta 3 años después, en que lo abandonó, aunque siguió en contacto con la actividad coral siendo 
Directora del Coro de Sindicatos y formadora y directora de coros escolares en diferentes colegios de la ciudad, participando en concursos de villancicos en época navideña y actuaciones en fiestas populares. Es decir, su trabajo coral se desempeñó tanto en actividades corales extraescolares o en campamentos juveniles de verano con la S.F, como con coros de adultos.

De su repertorio vocal, es obvio que siente una inclinación especial por la música coral. En especial, por el Canto Gregoriano y las canciones populares españolas. También le gusta mucho la polifonía del Renacimiento, la música del Barroco y la Zarzuela. La ópera no es el género que más haya cultivado, aunque durante su formación académica estuvo presente. Sin embargo, lo que realmente le gustaba eran los mencionados géneros. Se decanta por la Escuela de Canto Italiana, y le ha gustado mucho el trabajo realizado por grandes divas como María Callas, Victoria de los Ángeles y Montserrat Caballé. Después de tantos años de docencia, recuerda haber trabajado con voces muy buenas y bonitas.

\section{MARÍA DE LOS LLANOS PÉREZ RAYA}

Siempre, totalmente, únicamente la Música... Fue todo cuando era estudiante, cuando fui profesional y lo es ahora que soy jubilada.

Ma de los Llanos Pérez Raya, conocida como Llanitos, es natural de Albacete, aunque pasó su infancia tanto en Os de Balaguer (Lérida), como en Casas Ibáñez (Albacete) y Albacete capital.

Estudió el Grado Elemental y Profesional de Solfeo y Canto en el Real Conservatorio de Música y Danza de Albacete. En 1974 obtiene el Título Profesional de Canto, expedido por el Conservatorio Superior de Música y Escuela de Arte Dramático y Danza de Murcia, de acuerdo con las disposiciones del Decreto 2618/1966, con aptitud legal para el ejercicio del Profesorado. Se graduó obteniendo el Premio Fin de Carrera. Dentro de su trayectoria como alumna, destaca a los profesores de su Real Conservatorio de Música y Danza de 
Albacete, Daniel Martín (Director del centro, profesor de Solfeo), Pilar García Franco (profesora de solfeo y conjunto coral), Concepción Fernández-Cordero Picazo, profesora de canto en todos los cursos académicos y las diversas competencias de la asignatura.

Respecto a la Escuela de Canto a la que se vincula, en cuanto a lo que el ejercicio de la docencia en el Real Conservatorio se refiere, siempre se ha tenido que atener a la «Escuela general de canto lírico» que se establecía en la legislación para la su enseñanza en los Conservatorios. Al margen de esta obligación legal en lo docente, en lo personal se ha sentido identificada con las técnicas de canto de Lilly Lehmann, y ha estudiado las técnicas de Lehmann, Dr. Morton Cooper, Madeleine Masión... etc.

Llanitos ha disfrutado de las dos caras del mundo artístico sin considerarlas reñidas, del mismo modo que ha podido conciliar su vida profesional con la vida familiar. En lo que a su profesión como docente se refiere, primero como becaria (1973-1976) y luego como profesora funcionaria de carrera tras haber aprobado la oposición hasta 2013, declara que su principal objetivo dentro de la formación del alumnado ha sido «crear un planteamiento para hacer completa nuestra enseñanza y para que la formación de los alumnos alcanzara tanto las metas teóricas de los programas como las prácticas que exige la profesión. En tal sentido, iniciamos el montaje y representación de obras tanto para solistas como para conjuntos».

Bien es cierto, todos hemos sabido que el Real Conservatorio realizaba muy buenos montajes de obras, bien ambientadas en vestuario y decoración, con buen nivel musical, coreográfico y escénico, y esto ha sido gracias a ella. Los alumnos tenían ilusión por subirse a un escenario y desarrollarse plenamente como artistas. Entre los títulos representados, sobresalen «El Barberillo de Lavapiés» (Barbieri); «Bastian y Bastiana» (Mozart); «El chaleco blanco» (Chueca); «La Gran Vía» (Chueca), «La Creación» (Hayden); «Compositoras a través del tiempo»: un homenaje a María Malibrán, Clara Schumann, Carmen Ibáñez y Elena Pajares; «Misa Conmemorativa de la Coronación Canóniga de la Santísima Virgen de los Llanos», «Tonadilla 
Lírica», numerosos conciertos de Navidad, Semana Santa, Santa Cecilia...

Con independencia de las actividades complementarias con de sus alumnos que se reflejan anteriormente, ha desarrollado durante varios años una colaboración con los profesores de música de varios institutos de la capital, consistente en la preparación previa durante el curso por parte del titular de la asignatura y sus alumnos, de los textos de autores clásicos de unas obras musicadas que posteriormente serían interpretadas en recital. Esta previa preparación consistía en el análisis por parte de los alumnos de los autores y su época, estilo, contenido de la obra y cuantos datos se pudieran considerar dentro del nivel académico del alumnado. En algunos casos se llegó a proponer por los alumnos letras de canciones para obras de música clásica.

La formación superior de canto de Llanitos se vio reforzada con numerosos cursos de canto, clases magistrales, simposium y seminarios, todos ellos muy diversos entre sí. Aquellos más destacables en los que ella ha participado como alumna han sido: «Curso Nacional de Música y Movimiento Elemental y Aplicación a Educación Especial», impartido por el Mozarteum de Salzburgo en Albacete en 1971; «Curso de Metodología Musical», celebrado en Budapest y Kecskemét (Hungría) en 1980; «Curso de Ortofonía, Canto y Dicción», en Madrid en febrero de 1982.Respecto a la formación directa que ha recibido en clases magistrales, hay que destacar: «Lecciones magistrales sobre el Canto», impartidas por el tenor Alfredo Kraus en Madrid del 1984, por Monserrat Caballé, en Madrid del 1988 y por Luis de Pablo, en Madrid del 1989.

Otra cuestión relacionada con la voz que ha sido del interés de la cantante, es lo referente a la voz cantada, el cuidado de la voz, la voz hablada.... Por ello, ha participado también en otros cursos complementarios a su formación en este ámbito. Los más destacables son «Jornadas Internacionales sobre la Voz Cantada», en Bilbao de 1989; «Primeras jornadas Castellano Manchegas sobre Canto y Dicción», en Toledo de 1990; «Jornadas de Audiofonología», en fe- 
brero de 1990; «Curso de rehabilitación vocal de disfonías funcionales y orgánico funcionales», en Madrid de 1998.Así mismo, ella como profesional ha impartido cursos, seminarios, charlas y conferencias sobre la voz y su cuidado desde 1989 hasta 2005. Algunos de los títulos más importantes de dichos eventos son «Ortofonía»; «Ortofonía y Escuela»; «Educación de la voz»; «Reeducación vocal para docentes», «La voz, su prevención y recuperación».

Respecto a los concursos, no ha sido lo que más le haya atraído, ya que solamente ha participado en el Premio Fin de Carrera que se establecía como oficial en estos estudios. Ganó el «Premio Fin de Grado» de la Asignatura de Canto, previas las pruebas correspondientes en el Conservatorio Superior de Murcia el día 22 de noviembre de 1974. Sin embargo, sí que ha sido miembro de muchos jurados en numerosísimas ocasiones en concursos tanto de entidades privadas como oficiales. Participó regularmente en todos los concursos provinciales de las representaciones de las diversas localidades provinciales en las festividades navideñas, en convocatorias de pruebas de canto y grupos de la famosa feria de Albacete, y en los concursos de Juventudes Musicales de Albacete.

Como ya se ha mencionado, Llanitos ha tenido una larga vida como intérprete a nivel provincial, sobre todo. Ella ha amado el escenario, la representación artística, la puesta en escena... Aun sabiendo que era duro y sacrificado. Para ella, todas las actuaciones han sido importantes, muy importantes, especialmente las que han estado dedicadas al mundo joven, pues siempre ha dado prioridad al alumnado y las jóvenes promesas. De nuevo destaca las actuaciones con los institutos y aquellas dedicadas a las Juventudes Musicales, sin olvidarnos de aquellas en las que ha permitido a sus alumnos ser los protagonistas de la actuación.

En relación al extenso repertorio que ha abordado, con mucho gusto ha cantado lied, ópera, zarzuela y sudamericana. Algunas de las obras más representativas para ella son:

- Arias antiguas: A.Falconieri; G.B. Buononcini; A. Caldara; I. Rosi 
- Lied: W.A.Mozart; F.Schubert; J. Brahms.

- Música española: J. Rodrigo; J. Turina; C. Halffter; M. Falla.

- Música sudamericana: C. Guastavino; H. Villa-Lobos.

- Ópera Antigua: A. Falconieri; Buenocini; R.Arne; G.F. Häendel

- Ópera: Puccini; Donizetti; G, Verdi; Rossini y Weber

- Oratorio: Bach, Häendel, R. Arne.

- Zarzuela: Díaz Giles, R. Millán, A. Vives

Algunos grandes artistas que le han servido de referencia son Dietrich Fischer-Dieskau, Cecilia Bártoli, Feliciti Lott, Plácido Domingo, Teresa Berganza.

Dado sus muchos años de experiencia son muchos sus alumnos sobresalientes, en ellos Fuensanta Morcillo, Eva Badía, Ma del Carmen González Villada, Mํaㄹ del Prado Rolando, Elvira García, entre otros.

Pese a que su experiencia en el centro donde ha impartido clases ha sido positiva, su opinión sobre la calidad del Plan de Estudios de Canto dice que lo primero que hay que tener en cuenta es que los Centros que han de impartir esta disciplina deben contar con los medios necesarios para poder llevarla a cabo. «Medios suficientes tanto personales, como económicos, materiales y temporales. Por bueno que pueda ser el diseño de un Plan de Estudios, si no puede llevarse a cabo con todos estos medios, estará destinado al fracaso».

Finalmente, sobre sus recuerdos de juventud sobre la actividad musical en la capital son francamente tristes. Exceptuando la actividad cultural de la Caja de Albacete, luego llamada Caja de Ahorros de Albacete, que fue el motor de la actividad cultural, tanto musical como literaria y teatral durante todos los años sesenta, setenta y mediados los ochenta a través de su departamento de Obra Social, que activaba, específicamente, el ambiente musical con numerosos actos de esta materia. Posteriormente la iniciativa específica para crear un ambiente musical de afirmación «clásica» corrió a cargo de Juventudes Musicales, pero -al parecer- la falta de respaldo económico de las administraciones públicas impidió un desarrollo mayor. 
En lo que a la influencia directa o indirecta que ha tenido su actividad y persona en el panorama cultural y social de la ciudad, Llanitos declara «Con toda modestia debo dejar constancia de mi desconocimiento real de estas posibles formas de influencia en el ambiente cultural musical». Aunque es cierto el elevado número de recitales, conciertos y representaciones que su Conservatorio ha tenido, bien directamente o bien indirectamente con la Banda Municipal que dirigía el mismo director que el del Centro, Daniel Martín Rodríguez, han tenido su influencia en nuestra sociedad tan abandonada de esta materia. Puede afirmar que durante todos sus años de actividad ha recibido expresiones, mensajes y respaldo de numerosísimas personas tanto adultas ajenas a la enseñanza como de los propios alumnos que en el comienzo de sus estudios veían en los maestros un referente y un motivo para estudiar. No obstante, con la misma modestia con que inició el comienzo de su respuesta, quiere dejar constancia de que los cerca de cincuenta años que le ha dedicado a la actividad musical han tenido buena proyección e influencia en el sentir y carácter cultural musical de nuestra provincia.

Para concluir con el testimonio recogido, considero llamativo destacar los numerosos obsequios culturales que la soprano ha recibido: poemas, canciones, cuñas de prensa, artículos en el periódico local incluso preciosos cuadros y retratos de ella misma o con su familia.

\section{ELISA BELMONTE USEROS}

Yo no elegí el canto, el canto me eligió a mí.

Comienza su formación como licenciada en Filosofía y Ciencias de la Educación, especializándose en Organización y Orientación Escolar por la Universidad de Valencia en 1973. Tras esto, toma contacto con el Canto y la música, asistiendo a las Master Class de canto de Lauri-Volpi y de dramatización de su esposa María Ros en el Conservatorio Superior de Valencia en 1977. Fue alumna de Alfredo Kraus en las primeras Lecciones Magistrales que dio en Madrid 
en el Teatro Real en 1984. Este mimo año termina sus estudios de canto en Grado Elemental en el Conservatorio de Albacete en 1984 con la profesora Emilia Muñoz. Un año más tarde, consigue en 1985 en Valencia, el Título Profesional de Solfeo y de Música. Más tarde, tuvo el gusto de asistir las únicas Lecciones Magistrales que Montserrat Caballé dio en Madrid en el Auditorio Nacional en 1988. A ello hay que sumarle que fuese alumna de las Master Class del barítono Gino Becchi en el Liceo de Barcelona y con Paul von Schilavsky director del Mozarteum de Salzburgo. Finalmente, obtiene el Diploma de Cantante de Ópera en Escuela Superior de Canto de Madrid 1993 junto con el Título Superior de Cantante Especializada en la misma escuela en 1995. En esta escuela fue alumna de Isabel Penagos y Ana Higueras. Terminada la Escuela, estudió con el tenor Francisco Ortiz. Otros maestros que han influido en su carrera son los pianistas Miguel Zanetti y Féliz La Villa. En la Zarzuela, destaca a José Antonio Torres.

La Escuela de Canto a la que se vincula es la Escuela Español y el estilo musical con el que se identifica es la Zarzuela y la canción española de los siglos XIX y XX, la cual es parte fundamental de su repertorio. Ha grabado diversos discos de ópera y zarzuela, así como de Música y poesía, destacando «Paseo por la Poesía, De Garcilaso a Rafael Alberti» y «Entre Cervantes, Lorca y Machado». Actualmente, se considera que desarrolla una intensa labor de investigación y recuperación del Repertorio Español.

Por cantantes de referencia, tiene a Pilar Lorengar en música española, a Montserrat Caballé y Victoria de los Ángeles en internacional y ópera y a Teresa Berganza en zarzuela y música española. Respecto a los cantantes varones, dice que Alfredo Kraus siempre y a veces a Plácido Domingo, Pavarotti o Kauffman. De las grandes figuras internacionales, destaca a la siempre diva, María Callas, a Leontine Price, Anna Netrebko y Elina Garança. Del repertorio que muchos de ellos han interpretado, destaca D. Giovanni de Mozart, La Bohéme y Tosca de Puccini, La Traviata y D. Carlo de Verdi, así como la música vocal española. 
Ha estrenado obras especialmente dedicadas a ella en lugares tan importantes como el Palau de la Música de Valencia, Filarmónica de Málaga, Teatro Monumental de Madrid, Centro para la Difusión de la Música Contemporánea Reina Sofía o en el Museo Thyssen Bornemisza, así como a Festivales Internacionales en Austria, Italia , Francia, República Checa, EEUU, Canadá, Filipinas y cono sur americano.

Dentro de la línea de la interpretación musical de estilo zarzuela, ha interpretado principalmente «Luisa Fernanda», de Moreno Torroba, con el Director Oscar Barrientos en el Teatro Abril de Guatemala; La del Manojo de Rosas, de P. Sorozábal en «Amigos de la Zarzuela» de Valladolid; La del Soto del Parral, de Soutollo y Vert con la Compañía José Izaga en Logroño y La Rosa del azafrán, de J. Guerrero para Tele-Roda en Albacete. Destacables son muchas de sus actuaciones internacionales en lugares tan prestigiosos como la Asamblea General de la UNESCO en Paris (Francia); el Palacio de Naciones Unidas, ONU. en Ginebra (Suiza); el Carnegie Hall de Nueva York (USA); el Wiener Musikverein, Sala Brahms de Viena (Austria) y el Palacio Nacional de Queluz, patrocinio Embajada de España en Lisboa (Portugal).

Es también reseñable su faceta como actriz, colaborando en películas con títulos como Amanece que no es poco y Tiempo después, del director José Luis Cuerda; Sabias disquisiciones de un suicida incidental, del director José Talavera.

Numerosos son los premios y reconocimientos que ha tenido, como por ejemplo Tribuno en Cultura Diario La Tribuna, Verdadera Dulcinea, Diario La Verdad, Premio del Consejo Social de la Mujer, la Cadena SER, Oso y Madroño de Plata de la Peña de Albacete en Madrid, Miembro de honor del Festival de Quintanar de la Orden, Premio Morales Nieva, Rosa del Azafrán de Oro de la Solana, Dulcinea Universal por el Ayuntamiento del Toboso, Premio Jacinto Guerrero de Música, por la Casa de CLM de Madrid. También ha sido Pregonera de la Feria de Albacete.

En cuanto a alumnos destacados, dice tener muchos en distintos puestos como cantantes solistas en España y en el extranje- 
ro, o como cantantes del Coro Nacional, Coro de RTVE, del Teatro Real o del Teatro de la Zarzuela, como profesores de Conservatorios, como directores de Coros, como cantantes de musicales, etc... También destaca a sus alumnos del Máster en Patología de la voz de la Universidad de Alcalá de Henares que son reputados foniatras o logopedas.

Respecto a las becas que ha obtenido, destacamos que ha sido seis veces profesora dentro del programa Erasmus de la ESCM en lugares como Francia, Italia y Finlandia. Además ha impartido Master Class en La Escuela Lírica Nacional de Montevideo, Master Class de Canto en el Conservatorio Chopin de Varsovia y Cursos de Voz en Perú, Brasil y Paraguay.

En el apartado de tribuales, ha sido Jurado en el Premio Lola Rodríguez de Aragón y del Premio de Investigación del IEA (Instituto de Estudios Albacetenses), así como miembro de los Tribunales de fin de curso y Final de Carrera de la ESCM. Aparte de esto, ha sido Miembro de Honor y Jurado del Festival de la Mancha en Quintanar de la Orden.

Como profesional docente, ha tenido una carrera larga, pues lleva ejerciendo como maestra y profesora desde 1971. Ha pasado por diferentes niveles y centros educativos, habiendo sido profesora del Real Conservatorio de Madrid y de la Escuela Superior de Canto de la capital, donde sigue dando clases hoy por hoy. Actualmente colabora en trabajos de Investigación con el profesor Pedro GómezVilda, Catedrático de Departamento de Arquitectura y Tecnología de Sistemas Informáticos, Director del Centro de Tecnología Biomédica Neu Vox de la UPM. Ha sido profesora-colaboradora del Instituto Ciencias del Hombre-Universidad de Alcalá. Ha impartido asignaturas del Máster en Patología de la Voz en la Escuela de Posgrado UAH, ha dado masterclass de Música Española y Zarzuela en el Conservatorio de Varsovia y de Canto en la Escuela Lírica Nacional.

Entre sus publicaciones destacan: «In memoriam», Carmina Useros. La Escuela Española de Canto. IEA. Albacete 2018; «Canto. Bases y Método»; «Educación, Ciencia y Cultura en España: Auge y colapso. Pensionados de la JAE», Notas al programa Fundación Juan 
March. «La Canción de salón del XIX». Boletín marzo 2008; Artículo referencia del Congreso de Música y Medicina de Alcalá de Henares. Revista Música y Educación. Madrid 2004. Doctora en Ciencias Médicas. Los Métodos de Canto en España. El Trac del cantante a través de los criterios diagnósticos de las nuevas tecnologías. Propuesta de un método de canto (UCLM, 2014).

Una de sus mayores luchas y preocupaciones ha sido la de regular los estudios de canto queriéndoles dar el mismo prestigio que a los estudios universitarios y elevarlos al mismo rango. Es la primera mujer en escribir un tratado de canto desde 1984.

Finalmente, sobre su impacto directo o indirecto en el desarrollo cultural y musical de Albacete, pone de relieve haber creado la Compañía Lírica Jacinto Guerrero, la cual ha contratado a muchos músicos y cantantes para nuestras producciones. Participó en el primer curso que se organizó de Ópera y Voz en Albacete y fruto del cual nació la Asociación de Amigos de la Ópera de Albacete. También fundó la AEMUV, Asociación Española de Música Vocal, de la que es presidenta y que destaca por la difusión de la música española. Participó en la primera obra que se hizo en la Región con coros de Albacete y Cuenca que fue el Réquiem de Mozart y que luego tuvo diversas actuaciones en Madrid y las comunidades de Valencia y Murcia.

«Siempre he luchado porque en los actos institucionales se cante o interprete música española y no se haga siempre con compositores extranjeros». Recuerda con cariño varias obras compuestas para ella por Gabriel Fdz-Alvez, Juan Pérez Rives y Encarna Beltrán Huertas. Además, Libro del Pedagogo y compositor Félix Sierra, titulado «Cantos del Aula» le fue dedicado. Otros recuerdos entrañables sobre su experiencia musical en la ciudad son que debuté en el Teatro Circo en 1982 con dos villancicos del Padre Josico, acompañada por la Banda Sinfónica Municipal. Después dio un concierto en el museo Arqueológico Provincial. 


\section{MARÍA GLORIA DOÑATE ALCANTUD}

Gloria (12 de Julio de 1965, Albacete) cuenta con una larga trayectoria de formación artística, la cual empieza desde su más tierna infancia cursando danza y continuó hasta ser Titulada en Grado Profesional de Danza Española. Pero su relación con el arte no quedó sólo ahí ya que siguió su formación hasta obtener el Título Superior de Piano y Solfeo y Teoría de la Música, en Alicante, en 1988. Posee el Grado Profesional de Canto (2016).

Los estudios reglados fueron cursados en Real Conservatorio de Música y Escuela de Danza de Albacete, Conservatorio Oscar Esplá de Alicante y finalmente en el Conservatorio Torrejón y Velasco de Albacete. El haber estudiado en diferentes escuelas y conservatorios le ha permitido trabajar con diferentes maestros, siendo destacados Do Salvador Seguí, profesor de Solfeo y Teoría de la Música y Dirección Coral. La especialista en pedagogía vocal, D ${ }^{a}$ Ana Luisa Chova con quien ha dado clases de canto, $\mathrm{D}^{\mathrm{a}}$ Gloria Fabuel con quien también ha podido aprender la disciplina y finalmente, $\mathrm{D}^{\mathrm{a}}$ Fuensanta Morcillo, profesora de canto de ambos conservatorios de Albacete. El repertorio con el que más a gusto se siente es la ópera de cualquier corriente y la zarzuela. Entre sus cantantes favoritas cuenta con dos maestras españolas, Teresa Berganza y Ainhoa Arteta. De corte internacional ha destacado a la rusa Anna Netrebko, Elina Garanca, y Joice Didonato. Dentro de su trayectoria profesional, María Gloria es soprano en la Agrupación «Symbolum Ad Fidem Per Artem desde el año 2010», con la que ha recorrido diversas iglesias de España en numerosos pases. Títulos destacados son «Regina Coeli», «Divina Unión» /sobre la Vida de Santa Teresa», «La Misericordia» y «Sabbathani». También ha cantado los Autos Sacramentales «Sabachthani», «Aquesta Divina Unión», «La Divina Misericordia», «Regina Coeli» con la agrupación 'Symbolum ad fidem per artem'.

Desde el año 1989 desempeña su labor profesional como profesora de Lenguaje Musical, instrumento complementario, coro y pianista acompañante de canto en el «Real Conservatorio de la Di- 
putación de Albacete». Además, es directora de numerosos coros, tanto infantiles como de adultos.

Otra faceta profesional a destacar es su labor de directora musical en la empresa de eventos musicales, «GD Bodas». Esta empresa da trabajo a números de músicos profesionales de la ciudad y provincia, los cuales actúan en diversos eventos como bodas, graduaciones...

En su experiencia como intérprete, destaca la participación en las zarzuelas "La rosa del Azafrán», en el año 1999 en la ciudad de Almansa. En esta actuación, montó los coros de la obra durante seis meses con el coro que ella dirige, llamado «Voces del Llano». También actuó de solista, del mismo modo que en otro montaje de la Zarzuela «Canto a Murcia», con la misma asociación. En esta desempeñó igual tarea.

Además, ha dado numerosos conciertos líricos como solita en ciudades como Albacete, Alicante, Murcia y Cartagena. Durante más de quince años, con su coro «Voces del Llano» ha actuado en León, Ponferrada, Madrid, Pinto, Ciudad Real, Cuenca; con numerosos encuentros corales en Albacete y provincia.

Cantó el Pregón de la Semana Santa 2019 de Albacete, en el Teatro Circo por mediación de la Asociación de Cofradías de Albacete, en particular, la Cofradía de las Angustias.

\section{ANA LUISA SÁNCHEZ ESPINOSA}

Conocida en el mundo de la lírica musical como Analuisa Espinosa, nació el 20 de abril de 1964 en Albacete. Formación académica, podemos destacar que posee varias titulaciones como el actual Grado de Magisterio, en Murcia en 1987; Profesor de Canto, Conservatorio Superior de Sevilla, 1993 y Licenciada en Historia y Ciencias de la Música por la Universidad de La Rioja 2011. Estudió canto en la Fondation Royaumont de París, becada por France Telecom y pudo estudiar con profesores como Daniel Ferro y Lorraine Nubar, ambos de la Juilliard School de New York. Dentro del estilo 
musical al que se vincula, se identifica con la técnica vocal propia de la Escuela de Canto Italiana, con la que ha podido protagonizar Operas, Zarzuelas y Conciertos en los más prestigiosos Teatros y Salas de Concierto de todo el mundo durante los últimos años.Su repertorio abarca el Lied, la Opera, la Mélodie Française y el Género Lírico español.

Su trayectoria profesional, puede dividirse en tres principales campos: interpretación, investigación y docencia. En cuanto a la interpretación es destacable que como soprano lírica ha realizado numerosas grabaciones para RTVE, Radio Clásica, RAI, TV Tevetsé de Rusia, La voz de Rusia Radio, etc.

Como investigadora y difusora de la cultura musical, ha impartido numerosos cursos y conferencias, además de publicaciones sobre Canto, Técnica Vocal e Historia de la Música. Entre sus logros caben las creaciones de el «Taller de Técnica Vocal» (para cantantes y para docentes) de la Escuela Municipal de Música de Hellín (20022005) y el Proyecto Experimental de Adecuación de las Enseñanzas de Canto, PEAEC., que se ha puesto en marcha en el Conservatorio Profesional de Música Jerónimo Meseguer de Almansa (Albacete), gracias al cual la especialidad de Canto ha adquirido gran notoriedad y visibilidad. Como profesora, además ha impartido cursos de técnica vocal y Curso Pautas de prevención y Patologías de la Voz.

$\mathrm{Su}$ experiencia en el escenario y sus conocimientos sobre repertorio y técnica vocal le han permitido participar como jurado en: Concurso Internacional de Habaneras y Polifonía de Torrevieja, 2015 y el Concurso de Canto de Abarán (Murcia), 2004, donde fue presidenta del tribunal.

Ha obtenido numerosos premios y galardones, destacando: Prix Spéciald'Opèra, Trofeo Jean Giraudeau, Marmande, Francia, 1995. Primo Premio Internazionale Eva Duarte de Perón, Italia, 1998. Medalla al Mérito Cultural y Artístico, Italia, 1996. Mención de Honor de la emisora internacional La Voz de Rusia, Moscú, 2007. Reconocimiento Especial por la difusión en todo el mundo de la obra vocal del compositor cubano Ernesto Lecuona, 2011. Mujer Desta- 
cada, por su labor en favor de la difusión de la Cultura. Ayuntamiento de Albacete, 2013.

Aparte de los galardones bien merecidos, hay que hacer referencia a sus actuaciones destacadas como por ejemplo, la de Concierto del Día de la Victoria retransmitido por televisión desde Moscú para todo el mundo en 2004 y el Recital con Andrea Bocelli en Tabiano Terme (Italia) en 1994. Sobre sus gustos, destaca a Reneé Fleming como cantante favorita, en la cual se ha inspirado en alguna ocasión.

Finalmente, es reseñable la gratitud que muestra hacia el público que la ha acompañado, escuchado y acogido en escenarios a lo largo de veinte años de carrera, al cual define como «cariñoso y entregado».

Juan José García Carbonell le dedicó los siguientes versos:« Mujer hermosa que a la gloria llega. Dulcinea preciosa por manchega, en las tablas de triunfo y de calvario».

\section{MARÍA DOLORES SANZ REDONDO}

Nació el 13 de marzo de 1970 en Salamanca. Es diplomada en Magisterio y posee el título grado profesional de música en la especialidad de Canto. Ha asistido como alumna oyente a clases magistrales de Monserrat Caballé y Renata Scotto. También ha asistido a cursos de técnica vocal impartidos por Ana Luisa Chova, Pilar Jurado y José López Ferrero. Dentro de su formación musical como cantante, es destacable Llanos Pérez Raya principalmente. También Ana Luisa Chova, David Mancebón, Fuensanta Morcillo y a nivel particular, Pilar Jurado y José López Ferrero. No se vincula a ninguna Escuela de canto. No se ha sentido interesada por la vía de la investigación ni de las publicaciones, sino que la música para ella ha sido el motor de su actividad profesional como docente.

Su actividad profesional se centra en la de profesora de música de Primaria, actualmente trabajando en el CEIP Castilla la Mancha de Albacete. En el aspecto musical, se dedica a la dirección de 
coros infantiles. Desde los 15 años ha cantado en coros, siendo la musical coral su especialización tanto a nivel laboral como interpretativo. Desde hace más de 10 años lleva siendo de directora de Aula Coral, un bonito proyecto musical basado en la enseñanza a infantes de pre- escolar y primaria de musical coral.

Como maestra de Educación Musical en Primaria, he realizado numerosos cursos sobre diferentes metodologías: Orff, Kodály, Willems y por supuesto, ha recibido cursos de técnica y dirección coral con: Elisenda Carrasco, Juan Luis Martínez, Marcelo Beltrán, Inmaculada Arroyo, Basilio Astúlez entre otros.

En su labor docente fuera del colegio, ha sido ponente en varios cursos de Educación Musical para Infantil y Primaria y ha participado como profesora de coro en el II y III Curso Nacional Método Suzuki en Mollina (Málaga). También ha sido galardonada por su involucración en la música, recibiendo varios premios como miembro de la Coral de Albacete en Cocentaina y Griñón. También es miembro de otros coros de bastante reputación en la ciudad, dirigidos por su padre y por su hermano, la Coral de Albacete, y el coro del Conservatorio Profesional «Tomás de Torrejón y Velasco». Además, en el presente forma parte del coro de cámara «Philomusica CLM».

Su repertorio se vincula principalmente a Haendel y la música coral, sintiendo mucho amor y respeto por la música barroca y el estilo clásico. No obstante, por formación también ha cantado ópera y zarzuela.

En respuesta a la pregunta de su cantante favorita, la entrevistada afirmó, «Sería imposible hacer una lista con mis cantantes favoritas, pero podría destacar a Victoria de los Ángeles, María Bayo, Isabel Rey, Ainhoa Arteta, Teresa Berganza, Kiri te Kanawa, Elly Ameling, Jessye Norman, Anna Netrebko, Cecilia Bartoli». Vemos que son muchas y todas ellas de primera clase, grandes profesionales de renombre mundial. Esto no quiere decir que mencionar a cantantes tan conocidas sea un tópico ni una forma simple de contestar quedando bien, sino que cuando se tienen ciertos conocimientos sobre una materia se pueden reconocer con mayor facilidad la calidad de los intérpretes en este caso. 
Desde su perspectiva personal y según su testimonio, cuando ella empezó a cantar en Albacete sólo existían dos coros, el Orfeón de la Mancha y la Coral de Albacete. No existían coros infantiles ni juveniles, por lo que podríamos decir que en este aspecto, la ciudad estaba atrasada con respecto al resto de provincias de la nación. Esto se vio subsanado cuando Albacete fue una de las provincias elegidas por la Fundación Juan March para potenciar la música junto con Cultural Albacete, hasta entonces, todos los encuentros corales habían sido organizados por la Diputación de Albacete.

Actualmente, considera que «hay que aplaudir la iniciativa de la asociación albacetense de amigos de la ópera de organizar el «I Concurso Nacional de Canto Ciudad de Albacete» que se realizó el 2 de diciembre de 2018. Podríamos concluir diciendo que para ella Albacete ha mejorado mucho en cuanto a lo que arte, música, cultura y educación se refieren.

Una de sus reflexiones: «Me siento muy orgullosa por haber despertado en ellos el amor por la música. Ojalá cuando sean grandes profesionales de la música recuerden que su primer acercamiento a la música fue en un coro infantil».

\section{MARÍA FUENSANTA MORCILLO ZAFRA.}

La voz es un reflejo del alma y de la persona.

María Fuensanta Morcillo Zafra, artísticamente, Fuensanta Morcillo, nace en Albacete el 18 de abril de 1976. Desde muy pequeña comenzó estudios relacionados con las artes, estudiando Danza Clásica en el Real Conservatorio de Música y Danza de la Diputación de Albacete y más tarde, complementando su formación artística estudiando flauta travesera en el mismo centro. Hasta entonces, no había mostrado un interés especial por el canto.

Tiempo más tarde, con 13 años, al escuchar al Orfeón de la Mancha, dirigido por Ramón Sanz y como soprano solista principal, Ana Luisa Espinosa, se decidió a que ella «también quería hacer eso». Decide entonces unirse al Aula Coral, animada por Ramón Sanz (di- 
rector) y su hija María Dolores Sanz (cantante) y así pues comienza los estudios de Canto Lírico Profesional en el Real Conservatorio de Música y Danza de la Diputación de Albacete. En este centro, estudia con Llanos Pérez Raya, con la que se inició en el mundo del canto, a la que describe como «sus cimientos» y de la que dijo: «todo lo que enseñaba, lo hacía con cariño. Se vaciaba en cada clase. Todo lo que sabía, te lo intentaba enseñar». «Llanitos tenía una voz muy bonita, dulce, ligera y cristalina». Gracias a ella, Juan Carlos Colón y Fermín Navarrete, Fuensanta pudo empezar a despuntar en el mundo lírico de Albacete. Podríamos decir que fueron sus primeros apoyos.

Entre los 16 y los 17 años realiza sus primeras actuaciones a nivel profesional con público, acompañada de Fermín Navarrete y otros maestros en el Auditorio Municipal y en la Iglesia de la Asunción, principalmente. La mayoría de estos conciertos eran de música popular, música española y con un interés no lucrativo sino benéfico. La música al servicio del bien común.

Con 18 años, terminado el Grado Medio o Profesional, animada por sus profesores, en especial, Julia Vigó (su profesora de Lenguaje Musical), viaja a Madrid e ingresa en la Escuela Superior de Canto, cursando en dicha institución sus estudios superiores durante siete años. En Madrid estudió con Aída Monasterio, «su maestra» y se vio muy bien acompañada en todo el repertorio que interpretó junto con la repertorista Celsa Tamayo. Entre las tres emprendieron sus actuaciones de un carácter más serio y aún más profesional debido a la experiencia que iba adquiriendo. Al terminar la formación reglada, decide ampliar conocimientos y viaja a Vienna para poder estudiar de manera particular con una ilustre profesora de la Volksoper Wien, allí establece su residencia durante dos años. Posteriormente, cambia de continente y viaja a los Estados Unidos para formarse con profesores particulares en Palm Beach (Florida), donde durante otros dos años, la maestra Virginia Zeani fue quien la formó y con la que tuvo una estrecha relación gracias al buen trato que recibió de ella. A los 24 años, continuó estudios en verano en la Academia Rossiniana de Pessaro. Otros profesores que ella destaca 
por haber formado parte de su vida musical son Suso Mariátegui, sucesor de Krauss, «excelente liderista con registro de tenor ligero», el tenor Raúl Jiménez, Ana Luisa Chova y Victoria de los Ángeles.

Respecto a los numerosos concursos en los que ha participado, de los que más reseñables le parecen, menciona el Concurso Aussensi (Barcelona) donde cantó en el Liceu y el Palau Catalán y quedó finalista. También cuenta de muchos concursos en Sevilla. Otro concurso que ha quedado en su memoria es el de Las Palmas, donde conoció a Suso. «Todos los concursos me han costado mucho prepararlos: el de Sabadell, el de Barcelona... pero todos me han valido la pena».

Entre los 24 y 25 años, viajó por toda Europa a diferentes Opera Studio. En Europa sobresalen las de Aix-en Provence y Pessaro; fuera del continente, estuvo involucrada en unas Opera Studio de Londres (durante tres años) y en la de Houston.

Gracias a estas oportunidades de formar parte de montajes y de asistir a otros, Fuensanta tuvo ocasión y obligación de abordar un vasto y complicado repertorio de soprano lírico-ligera que le ha acompañado el resto de su carrera, interpretando los principales roles para su voz en obras como Lucía de Lammermoor de Donizetti, La Sonnambula de Bellini y Gilda de Rigoletto de Verdi. Estas obras forman parte de su principal repertorio operístico. En cuanto a la Zarzuela, siente especial afinidad por Doña Francisquita y Bohemios, por ser las primeras que empezó a montar. De La Tabernera del Puerto afirma que es «completísima y bellísima. Sorozábal la escribió muy bien», por ello la ha cantado innumerables veces. Ante la pregunta de cuál es su repertorio favorito, da una respuesta común pero no incierta en este tipo de casos, y es que «hay tanto repertorio que no sabría por dónde empezar... Además, considero que todo es bello dentro de su estilo; hay que saber indagar en la partitura, el compositor, el personaje, el contexto... y siempre hacerla tuya. Si te identificas y la sientes, puedes lograr afrontarla con éxito».

Ha cantado como solista en numerosos teatros de reputada fama, como pueden ser el Teatro Real, en varios y distinguidos even- 
tos privados, en la Scala de Milán en un recital con finalistas de una OperaStudio, y recitales en el Palau y el Liceu con las perteneciente Orquesta escuela. Le encantó el Teatro de Las Palmas, donde hizo de manera completa las óperas de «Hansel y Gretel» de Engelbert Humperdinck y «El matrimonio secreto» de Dominico Cimarosa.

Ha actuado en EEUU, Reino Unido, Italia, Suiza, Alemania, Austria, Francia y, sobre todo, en España, donde cabe mencionar escenarios como el Palacio de Festivales de Cantabria, Teatro de la Maestranza de Sevilla, Teatro Cervantes de Málaga, Palacio de la Ópera de La Coruña, Teatro Circo de Albacete, Auditorio de Las Palmas de Gran Canaria, Auditorio de Tenerife, Centro Cultural de la Villa de Madrid, etc.

Las Escuelas de Canto con las que se vincula son la Italiana y la Americana, acerca de la cual declara «es mejor de lo que nos creemos, pues tiene muy claros los puntos de altura del canto».

Fue becada en una ocasión por una empresa internacional a través del Teatro Real y numerosas veces por el Ministerio de Educación por ser familia numerosa gracias a sus buenas notas. No obstante, la mayor parte de sus estudios y viajes fueron financiados por ella misma gracias a sus actuaciones cantando en bodas, eventos, coros de zarzuelas... cuya experiencia valora mucho por «haber conocido muchos teatros y mucha gente».

El curso 2018-2019, debuta como Jurado en el Primer Concurso de Canto Nacional de Albacete, certamen que surgió de su propia iniciativa y fue muy bienvenido por la ciudad y respaldado por los Amigos de la Ópera de Albacete, tuvo lugar en diciembre y se trabaja en la segunda edición.

No compone ni publica porque «se dedica a estudiar», sin embargo, sí le han dedicado obras y composiciones, como por ejemplo unas «Canciones Infantiles» de Adelino Barrios, las cuales guarda con mucho cariño y canta a sus hijos. Sus cantantes de referencia son Virginia Zeani, María Callas, Kiri Te Kanawa (a la que tuvo el gusto de escuchar en directo en Alicante y la emocionó) y Lucia Pop. De carácter nacional, Victoria de los Ángeles y Pilar Lorengar. Su músi- 
ca favorita es la música clásica vocal: ópera, zarzuela o canción, sin distinción. «Todo tiene su sitio, y bien hecho, cuando encuentras la esencia, es maravilloso». Insistí para que se declinase por un género en particular y dijo: «Hay mucha música por hacer. A día de hoy, no sé qué me llevaría a una isla desierta; aún no lo sé».

En su labor como docente, ha trabajado tanto en el Conservatorio de Cuenca como en los de Albacete, primero en el Conservatorio de la Junta de Comunidades de Castilla-La Mancha, «Tomás de Torrejón y Velasco» y luego en el de la Excelentísima Diputación. En su metodología destaca el trato personal con el alumnado y la importancia de saberlos comprender de manera individual. De este modo, conociéndolos uno a uno, se puede crear un grupo y trabajar a gusto. Ella dice: «he intentado hacer Escuela. Que cada uno sea individuo y sea su voz». Fuensanta en su forma de proceder con el alumno, rehúye todo tipo de comparaciones e intenta que «cada alumno trabaje, que llegue hasta dónde tenga que llegar».

Se muestra muy contenta con el alumnado que ha tenido, destacando a José Javier Sáez Ruíz, Elena Plaza Fernández, María del Valle Robles de Moya y José Miguel Soria Fernández, «La voz tiene un recorrido enorme, es un bagaje... la cuestión está en ir haciendo». En función del alumnado que se tiene, se pueden hacer muchas cosas. A la profesora le gusta embaucarse en diferentes proyectos, como por ejemplo, un oratorio de Haendel que hizo con dos de sus alumnas sopranos, un coro y orquesta. Más tarde, Vicent Ferragut, profesor de banda y orquesta del conservatorio de la Junta, le propuso poder rodar con sus alumnos por la zona de Valencia, a lo que todos aceptaron, pues eran una gran oportunidad. Estos recitales eran remunerados y suponía un alzamiento para todos. Otro ejemplo fue cuando montó «Dido y Eneas» con Juanma Cifuentes y Josemi Alarcón. Este año, con Paco Redondo, director del EA! Teatro, han hecho un montaje de un cuento en el cual se interpretaban por sus alumnos diferentes arias de ópera contextualizadas. Para Fuensanta es muy importante la palabra «proyectos», tanto a nivel personal e individual, en el cual «llegaré hasta donde pueda» como en lo que a montajes con sus alumnos se refiere. 
En la influencia que ha tenido en el patrimonio y el desarrollo cultural de Albacete, de manera indirecta subraya todas las veces que ha acudido a conciertos del tipo que fuesen, tanto para nutrirse de ellos a nivel personal como para tomar ideas aplicables en el aula, en la compañía, en su repertorio, en el Conservatorio... de manera directa, tenemos el hecho de su carrera profesional como intérprete solista, que se ha desarrollado mucho en Albacete al haber cantado numerosas veces en el Teatro de la Paz, Teatro Circo, Auditorio Municipal, Santa Iglesia Catedral, etc.; todos los montajes que ha realizado con sus alumnos, con la compañía «Cachivaches» y su iniciativa de crear el Primer Concurso Nacional de Canto de Albacete. También quiso destacar su labor como docente, la cual le apasiona, y el buen apoyo y recibimiento que ha tenido siempre en los conservatorios, nombrando a compañeros como Fermín, Llanitos, Juan Carlos Tolón, Mari Carmen Simón... e incluso las instituciones, con Ricardo Núñez, la Banda Municipal.

Ante la pregunta de «¿Qué destacarías más, la vida de intérprete o la de docente?», respondió: «nunca he sido tan matemática, no las podría dividir. Me ha apasionado y emocionado subirme a los escenarios, me ha revuelto el alma... Pero cuando llegaba y daba las clases y veo al alumno emocionado, ese fluir y esa unión entre el alumno y profesor, me hace igual de feliz».

Actualmente, compagina su labor artística con la de profesora del Real Conservatorio de Música y Danza de la Diputación y coordina la próxima celebración de la segunda edición del Concurso de Canto Lírico de la ciudad de Albacete.

Fuensanta es una persona que sin duda elegiría de nuevo el canto como forma de vida. Es algo que «le vino dado». Ella empezó con la danza porque visualizaba en la televisión actuaciones patinaje artístico y era como una llamada. Pero cuando sus padres comenzaron a llevarla a conciertos de música vocal del Orfeón de la Mancha y del Aula Coral, sintió una nueva llamada aún más honda que la primera. 
Declara que lo más infeliz que la ha hecho del canto han sido los fracasos sobre el escenario, no hacer las cosas perfectas después de tanto trabajo... por el contrario, lo que más feliz la ha hecho, ha sido poder sacar a relucir a través de la interpretación el trabajo esfuerzo y belleza de cada obra, así como la satisfacción personal que producen la alegría ajena del alumno que experimenta lo sublime del arte en general y del canto en particular. 